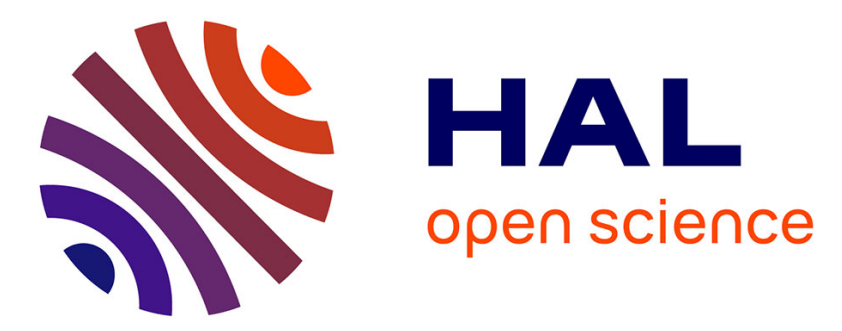

\title{
Recent Progress in Chemical Syntheses of Sphingosines and Phytosphingosines
}

\author{
Yangguang Gao, Xianran He, Fei Ding, Yongmin Zhang
}

\section{To cite this version:}

Yangguang Gao, Xianran He, Fei Ding, Yongmin Zhang. Recent Progress in Chemical Syntheses of Sphingosines and Phytosphingosines. Synthesis: Journal of Synthetic Organic Chemistry, 2016, 48 (23), pp.4017 - 4037. 10.1055/s-0036-1588311 . hal-01445047

\section{HAL Id: hal-01445047 \\ https://hal.sorbonne-universite.fr/hal-01445047}

Submitted on 24 Jan 2017

HAL is a multi-disciplinary open access archive for the deposit and dissemination of scientific research documents, whether they are published or not. The documents may come from teaching and research institutions in France or abroad, or from public or private research centers.
L'archive ouverte pluridisciplinaire HAL, est destinée au dépôt et à la diffusion de documents scientifiques de niveau recherche, publiés ou non, émanant des établissements d'enseignement et de recherche français ou étrangers, des laboratoires publics ou privés. 


\section{Recent progress in chemical syntheses of sphingosines and phytosphingosines}

\author{
Yangguang $\mathrm{GaO}^{\mathrm{a}, \mathrm{b}, 1}$ \\ Xianran $\mathrm{He}^{\mathrm{a}, \mathrm{b}}$ \\ Fei Ding $a, b$ \\ Yongmin Zhang ${ }^{c}$ *
}

${ }^{a}$ Institute for Interdisciplinary Research, Jianghan University, Wuhan Economic and Technological Development Zone, Wuhan 430056, People's Republic of China

${ }^{b}$ Key Laboratory of Optoelectronic Chemical Materials and

Devices of Ministry of Education, Jianghan University, Wuhan

Economic and Technological Development Zone,Wuhan

430056, People's Republic of China

Institut Parisien de Chimie Moléculaire, CNRS UMR 8232,

Université Pierre et Marie Curie-Paris 6, 4 Place Jussieu,

75005 Paris, France

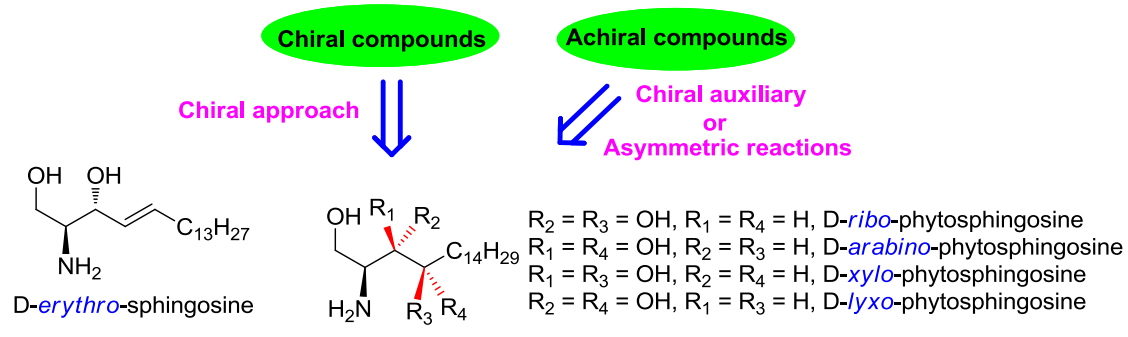

e-mail_yongmin.zhang@upmc.fr

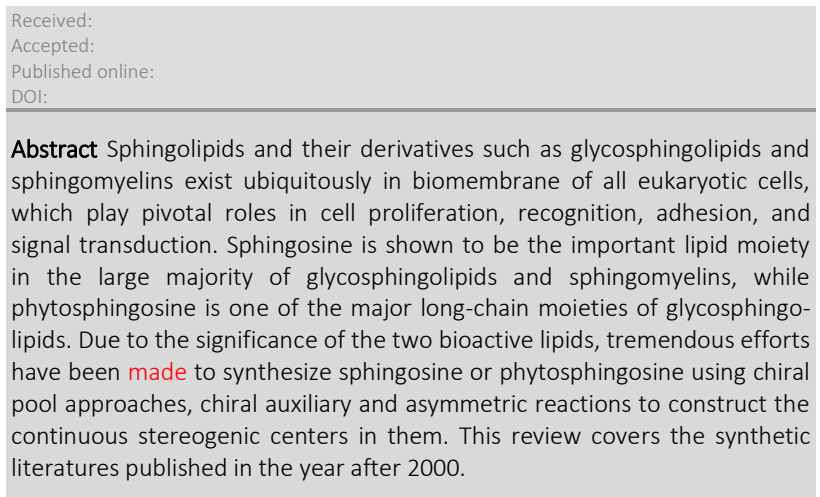

1 Introduction

2 Chiral Approach

2.1 Chirality from sugar

2.1.1 Chirality from mannose or mannitol

2.1.2 Chirality from D-lyxose

2.1.3 Chirality from D-xylose

2.1.4 Chirality from D-glucose and its derivatives

2.1.5 Chirality from D-galactose and its derivatives

2.1.6 Chirality from D-ribose

2.1.7 Chirality from D-fructose

2.2 Chirality from serine and its derivatives

2.2.1 Chirality from serine ester

2.2.2 Chirality from Garner's aldehyde

2.3 Chirality from D-ribo-phytosphingosine

2.4 Chirality from D-tartric acid and its diester

2.5 Chirality from other chiral precusors

3 Chiral auxiliary

3.1 Chiral sulfur auxiliary

3.2 Chiral N-containing auxiliary

4 Asymmetric reactions

4.1 Sharpless dihydroxylation reaction

4.2 Sharpless epoxidation and Shi's epoxidation reaction

4.3 Asymmetric aldol reaction

4.4 Sharpless kinetic resolution

4.5 Asymmetric aminohydroxylation and amination

5 Conclusions

Key words sphingosine, phytospingosine, synthesis, chiral pool, auxiliary, epoxidation

\section{Introduction}

Sphingolipids and glycosphingolipids are expressed on the surface of cell membrane and distributed throughout all eukaryotic cells, which are of physiological importance for cell growth, recognition, adhesion, neuronal repair, and signal transduction. ${ }^{1}$ Sphingonsine, an amino alcohol, assigned as [(2S, $3 R, 4 E$ )-2-amino-3-hydroxyoctadec-4-en-1-ol)](Scheme 1), which is major lipid moiety of various sphingolipids, has itself displayed potent inhibitory activity against protein kinase $C$ and plays key roles in cell signaling. ${ }^{2}$ Study on sphingosine has underwent a long time since its first isolation by Thudichum from human brain in $1884,{ }^{3}$ the correct relative structural confirmation of the key functional groups by Carter in 1947, ${ }^{4}$ and first total synthesis by Shapro and Segal in 1954. ${ }^{5}$ Phytosphingosine, one of the major backbone of glycosphingolipids found in higher plants, protozoa, yeast and fungi, ${ }^{6-9}$ is a sphingoid base incorprating a long aliphatic chain and a polar 2-amino-1,3-diol group at head end. The fixed amino function and variation in hydroxyl stereogenic centers of phytosphingosine leads to four diastereomers, which exhibit different activities and metabolisms. Phytosphingosine is also a bioactive lipid, and its glycosylated derivatives display hopeful antitumor and antivirus activity. 10-11 For example, D-ribophytosphingosine can work as a cytotoxic agent against human leukemic cell lines. ${ }^{12}$ In addition, D-ribo-phytosphingosine acts as hopeful heat stress signaling molecule in yeast. ${ }^{13}$

To note, there is an underlying disorder related to $\mathrm{D} / \mathrm{L}$ descriptors since two nomenclatures (i.e. amino-acid nomenclature and carbohydrate nomenclature) are employed for phytosphingosines. ${ }^{14}$ For the sake of consistency, a traditional carbohydrate nomenclature in the amino-acid sense is used in this review unless otherwise stated. 


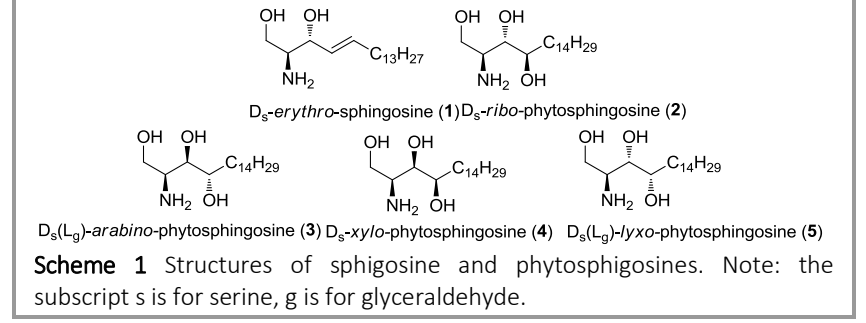

Because of the diverse biological activies and novel structural characters of sphingosines and phytosphingosines mentioned above, much attention has been drawn from biological and chemical community, especially from chemical community due to the scarcity of the two lipids in nature. To date, several reviews have been present in literatures. ${ }^{15}$ Herein, we would like to introduce some recent advance in chemical syntheses of sphingosines and phytosphingosines published from 2000 to 2015, the synthetic procedures would be discussed together based upon their structural similarity.

\section{Chiral Approach}

\subsection{Chirality from sugar}

\subsubsection{Chirality from mannose or mannitol}

Pandey has reported an enantioselective and concise synthesis of $(2 S, 3 R, 4 R)$-D-xylo-phytosphingosine with 7 steps in $36 \%$ overall yield utilizing $D$-mannitol triacetonide as chiral pool (Scheme 2). ${ }^{16}$ In his scheme, D-mannitol triacetonide was converted into $\beta$ lactam 7 according to literature's procedure ${ }^{17}$ to install all of the required stereogenic centers. Wittig olefination was employed for chain elongation followed by two-step reduction to give compound 8. Finally, full deprotection under acidic condition, then, peracetylation with acetic anhydride/pyridene gave $\mathrm{N}, \mathrm{O}, \mathrm{O}, \mathrm{O}$-tetraacetyl-D-xylo-phytosphingosine (10) in a good yield.

Mettu has accomplished the syntheses of tetraacetyl-D-ribophytosphingosine (16) and triacetyl-D-erythro-sphingosine (18) using a common intermediate $\mathbf{1 1}$ obtained from cyclohexylidene protected D-glyceraldehyde (12), which was readily prepared from D-mannitol (Scheme 3). ${ }^{18 a}$ The key steps included high diastereoselective Sharpless asymmetric epoxidation, regioselective epoxide-opening reaction by azide nucleophile, and Wittig olefination. Panza also adopted compound $\mathbf{1 2}$ as chiral pool to synthesize 3-O-benzoyl azidosphingosine 22. ${ }^{18 b}$ Nucleophilic addition of the Grignard reagent to D-glyceraldehyde gave the propargylic alcohol 19 with low diastereoselectivity (syn/anti = 4:6). The undesired anti addition product was recycled through deacetylation followed by Mitsunobu inversion. Different from triflate or mesylate as leaving group in literatures, chloromesylate

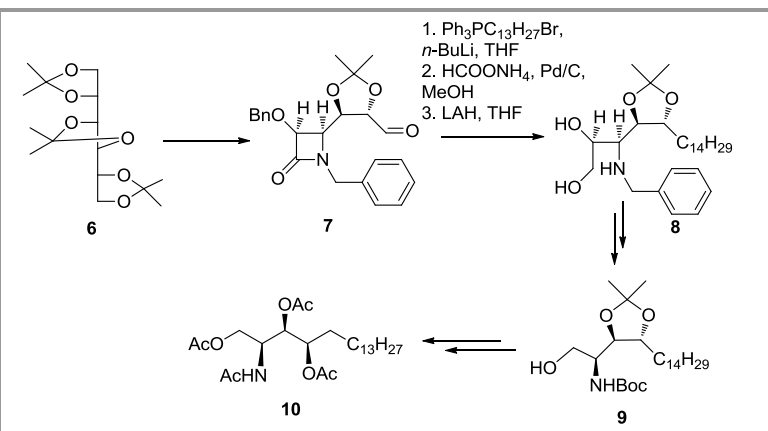

Scheme 2 Synthesis of N,O,O,O-tetraacetyl-D-xylo-phytosphingosine (10) from D-mannitol triacetonide (6). was utilized as leaving group which was subjected to displacement by azide nucleophile to afford azidosphingosine in a very satisfactory yield.

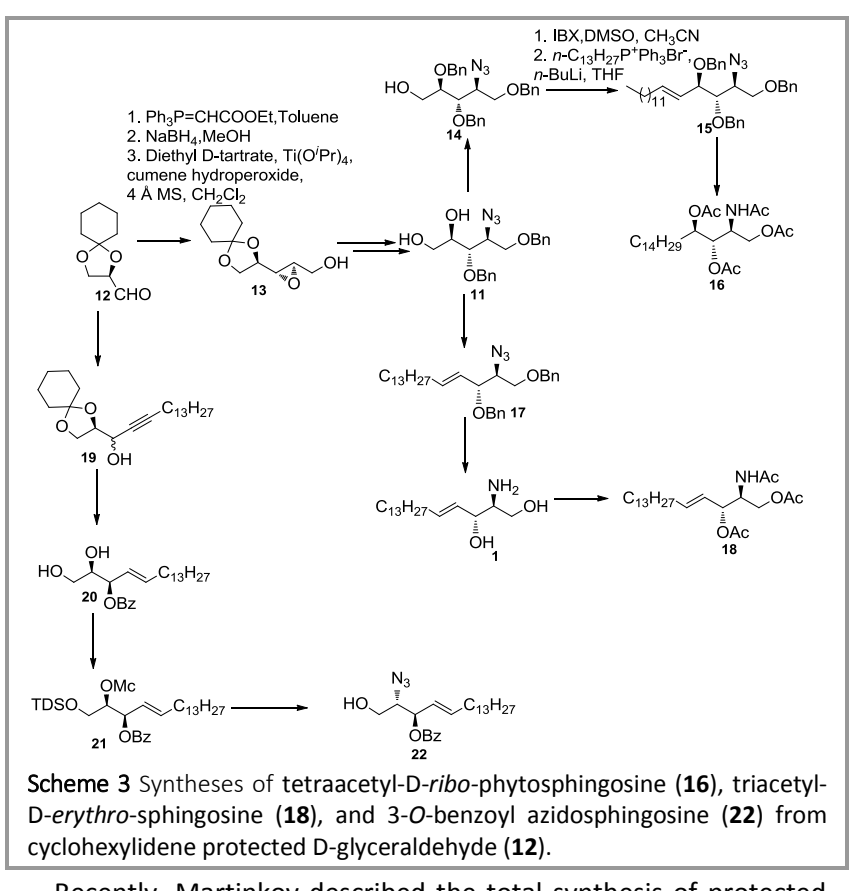

Recently, Martinkov described the total synthesis of protected Lg-arabino-phytosphingosine (31), L-ribo-phytosphingosine (28) from 2,3:5,6-di-O-isopropylidene-D-mannofuranose (Scheme 4)(g means for glyceraldehyde). ${ }^{19}$ The pivotal reactions involved [3,3]sigmatropic rearrangement to introduce the desired amino functionality, and chain elongation through Wittig olefination. Notably, thermal Overman rearrangement of $\mathbf{2 4}$ furnished inseperable rearranged products in a low yield and pool diastereoselectivity, while the use of microwave heating afforded high-yielding of rearranged products and greatly shortened reaction time. The protected L-ribo-phytosphingosine (28) could be accessible from rearranged product $\mathbf{2 5 b}$ through several manipulations. Utilizing the same procedure as described for the preparation of protected L-ribo-phytosphingosine (28), synthesis of compound $\mathbf{3 1}$ was achieved from compound 25a. An alternative route for preparation of $\mathbf{3 1}$ was commenced with allylic thiocyanate $\mathbf{2 9}$ according to the similar procedure for synthesis of compound $\mathbf{2 8}$. Though aza-Claisen rearrangement of 29 was carried out in modest yield, displayed better stereoselectivities than those observed for the Overman rearrangement of trichloroacetimidate 24.

Also from 2,3:5,6-di-O-isopropylidene-D-mannofuranose, Lin reported a concise and efficient synthesis of D-ribo-phytosphingosine (2), which employed eight-step conventional manipulation in $57 \%$ overall yield using Wittig olefination and azide nucleophilic replacement as key reactions (Scheme 4). ${ }^{20}$ 


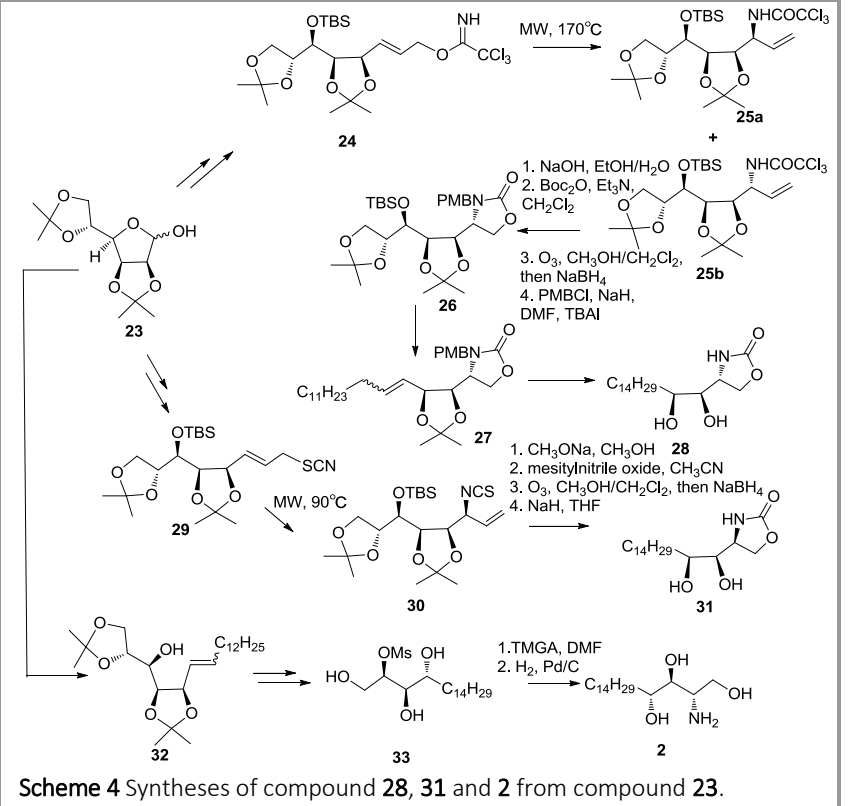

2.1.2 Chirality from D-lyxose

A short and very efficient route for synthesis of D-ribophytosphingosine from $\mathrm{D}$-lyxose was reported by Lin group in 2003 (Scheme 5). ${ }^{21}$ In his work, D-ribo-phytosphingosine (2) was prepared from D-lyxose over 6 steps in $28 \%$ overall yield using Wittig olefination and substitution by tetramethylguanidinium azide (TMGA) as crucial steps. A similar synthesis of D-ribophytosphingosine was also achieved by Lin group, in which both Wittig olefination and olefin cross-metathesis (CM) were adequately employed to extend carbon chain. ${ }^{22}$ The later strategy seemed not to be concise compared to the former; however, it afforded rapid access to syntheses of the phytosphingosine derivatives.

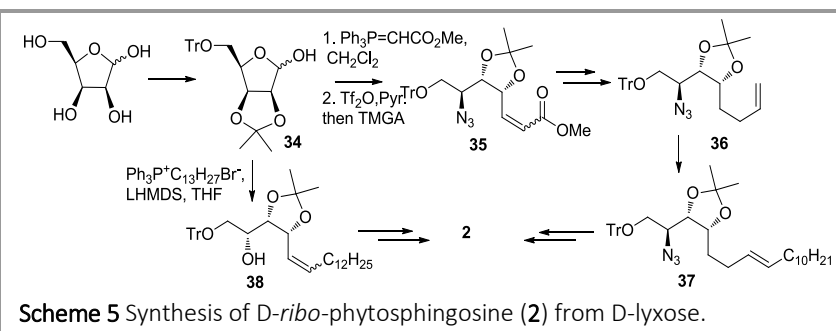

\subsubsection{Chirality from D-xylose}

Panza has reported the synthesis of 3-O-benzoylazidosphingosine (22) from 3,5-O-isopropylidene-D-xylofuranose using Peterson olefination and allylic displacement by Grignard reagent as key steps (Scheme 6). ${ }^{23}$ The deficiency of the strategy was low trans selectivity $(E / Z=2 / 1)$ in allylic displacement. Still from cheap D-xylose, Kocienski has reported a twelve-step synthesis of the Derythro-sphingosine utilizing a 1,2-metallate rearrangement as the key step. In addition, Brook rearrangement and substitution by diphenylphosphoryl azide (DPPA) via Mitsunobu reaction were equally indispensable for the synthesis. ${ }^{24}$ This synthesis provided a novel strategy for effective construction of trans double bond.

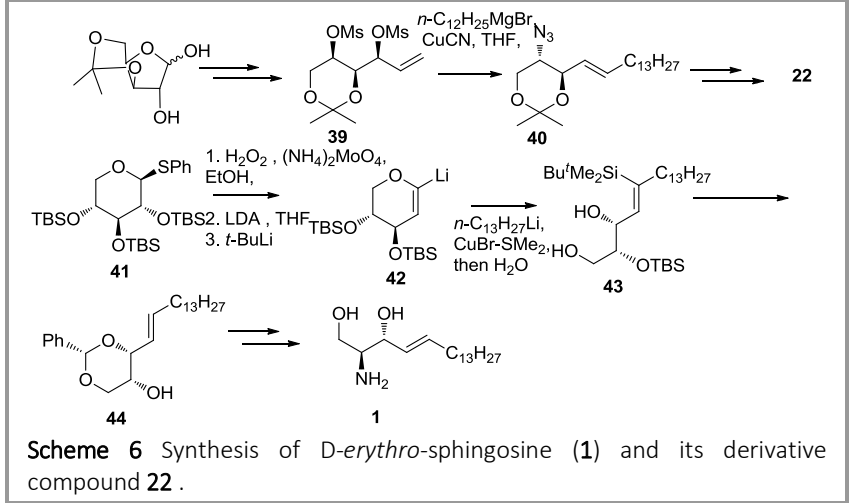

\subsubsection{Chirality from D-glucose and its derivatives}

In 2012, Rao has accomplished the synthesis of acetyl derivative of $\mathrm{L}_{\mathrm{g}}$-lyxo-phytosphingosine (48) commencing with known 1,2:5,6di-O-isopropylidene-D-glucofuranose derived from D-glucose (Scheme 7). ${ }^{25}$ In this work, Z-selectivity Wittig olefination was employed as key step to elongate carbon chain though stereochemistry of the double bond was unnecessary because of the subsequent hydrogenation. As shown in Schme 7, the important intermediate 49 was also prepared from 1,2:5,6-di-Oisopropylidene-D-glucofuranose over 4 steps. Synthesis of Derythro-sphingosine (1) was achieved by Dhavale via E-selective olefin cross-metathesis between compound $\mathbf{4 9}$ and long-chain terminal alkene in $65.4 \%$ overall yield. ${ }^{26} \mathrm{~A}$ direct synthesis of 16 from $\mathrm{D}$-glucosamine hydrochloride via the $\mathrm{D}$-allosamine derivative 50 as key intermediate has been reported by Hung in 2002.27 Similar to the synthesis of acetyl derivative of $\mathrm{Lg}_{\mathrm{g}}$-lyxo-phytosphingosine (48), Z-selectivity Wittig olefination was employed as well for extension chain to synthesize tetraacetyl-D-ribo-phytosphingosine (16). Besides, amino-azido conversion and highly regioselective benzoylation were also essential to this work.

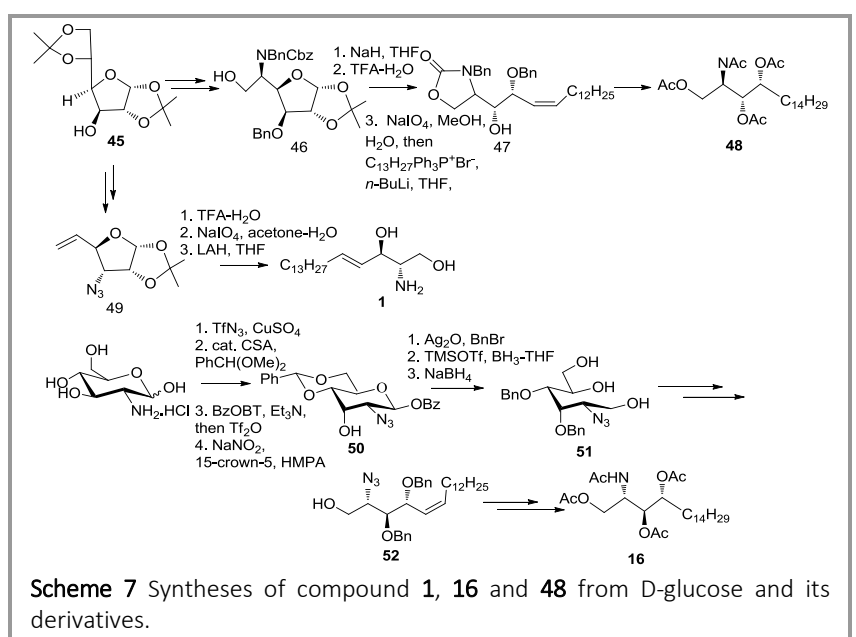

Bundle has utilized selective iodination, zinc-mediated reductive ring-opening reaction and olefin cross-metathesis as crucial steps to prepare tetraacetyl-D-xylo- and D-ribo-phytosphingosine (10 and 16) starting from the methyl $\beta$-glycosides of D-GlcNAc (53a) and D-AllNAc (53b), respectively (Scheme 8). ${ }^{28}$ The spotlight of the synthesis was excellent $E / Z$ selectivity $(E / Z=19: 1$ for $\mathbf{5 5 a}$, only $E$ for 55b) of olefin cross-metathesis (OCM), and the OCM could be applied to synthesize phytosphingosine derivatives with desired alkyl chains length. 


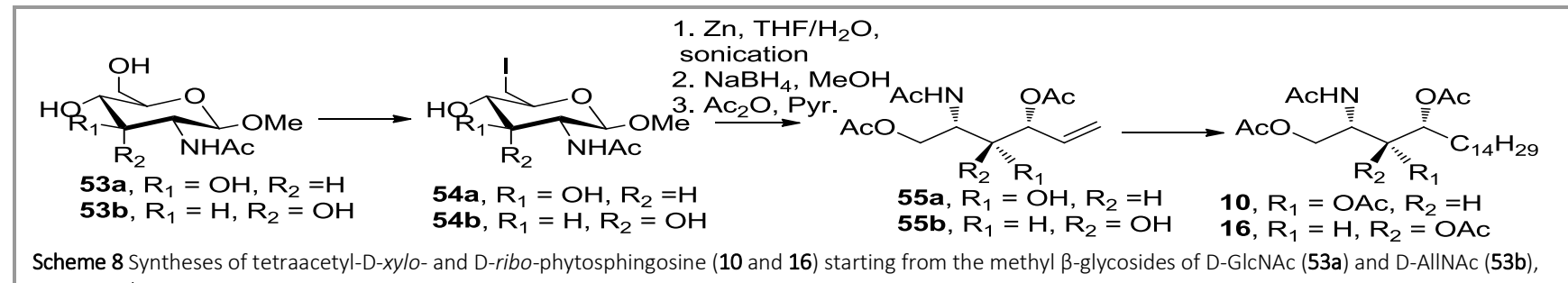
respectively.

\subsubsection{Chirality from D-galactose and its derivatives}

Duclos Jr reported a concise and conventional synthesis of Derythro-sphingosine (1) starting from D-galactose over 7 steps in 2001 (Scheme 9), ${ }^{29 a}$ which was based on the previous protocol adopted by Schmidt in $1988 .^{30}$ The key step was Wittig olefination between 1,3-O-benzylidene-D-threose (56) and $n$-tetradecyl ylide to exclusively form trans double bond. The same protocol was utilized by Demchenko to synthesize L-erythro-sphingosine (ent-1) from 1,3-O-benzylidene-L-threose (prepared from L-arabitol) in 2010. ${ }^{29 b}$ In 2000, Schmidt also utilized 1,3-O-benzylidene-Dthreose for preparing D-ribo-azidophyto-sphingosine (59). ${ }^{31}$ Highlight of this work involved stereoselective addition of 1,3-Obenzylidene-D-threose by $n$-tetradecyl magnesium chloride to exclusively produce chiral hydroxyl at C4 position, and regioselective mesylation at $\mathrm{C} 2$ position.

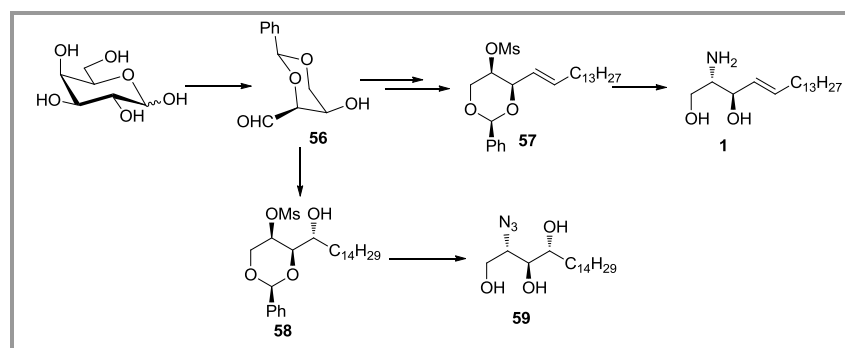

Scheme 9 Syntheses of D-erythro-sphingosine (1) and D-ribo-azidophytosphingosine (59) from 1,3-O-benzylidene-D-threose.

In 2008, Ye group accomplished a facile synthesis of tetraacetylD-ribo-phytosphingosine (16) over 5 steps in $74 \%$ overall yield from 3,4,6-tri-O-benzyl-D-galactal (Scheme 10). ${ }^{32}$ Spotlight of this synthesis included a high-yielding Wittig olefination of lactol 60 and one-step azide substitution via Mitsunobu reaction.

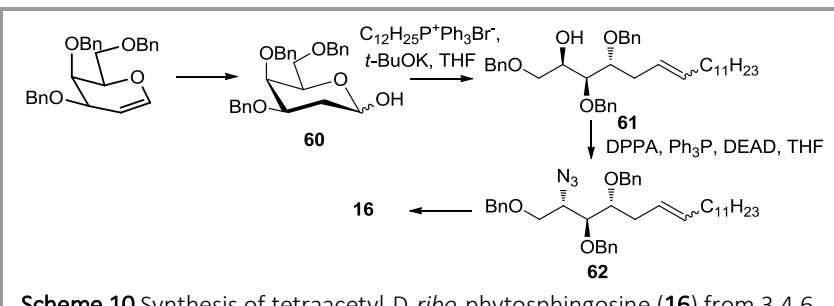

Scheme 10 Synthesis of tetraacetyl-D-ribo-phytosphingosine (16) from 3,4,6tri-O-benzyl-D-galactal.

\subsubsection{Chirality from D-ribose}

Very recently, Martinková ${ }^{33}$ accomplished the syntheses of tetraacetyl-D-arabino-phytosphingosine (66), tetraacetyl-D-ribophytosphingosine (16) starting from D-ribose on the basis of the same procedures as described for preparation of their enantiomers in 2011 (Scheme 11). ${ }^{34}$ The key step involved azaClaisen rearrangement of allylic thiocyanate 64 to afford rearranged products $65 \mathrm{a}, \mathbf{6 5} \mathrm{b}$ in an approximate ratio of 3:1 with $50 \%$ yield, which was further used to synthesize compound 66 and 16, respectively. Unlike Martinková's protocol, Sutherland employed Overman rearrangement of allylic trichloroacetimidate to install the chiral amino group of compound 70a as a single diastereomer in a satisfactory yield (72\%) (Scheme 12). ${ }^{35}$ While the other two stereogenic centers of phytospingosines were also derived from D-ribose. Thus, a new access to D-ribophytosphingosine (2) was achieved using Overman rearrangement, trans-selective $\mathrm{CM}$ reaction, and stereoselective reduction of unsaturated ketone via CBS-reduction as key steps. The synthesis of L-arabino-phytosphingosine (ent-3) was prepared from $69 \mathrm{~b}$ according to the same preceduce as decribed for $\mathbf{2}$.
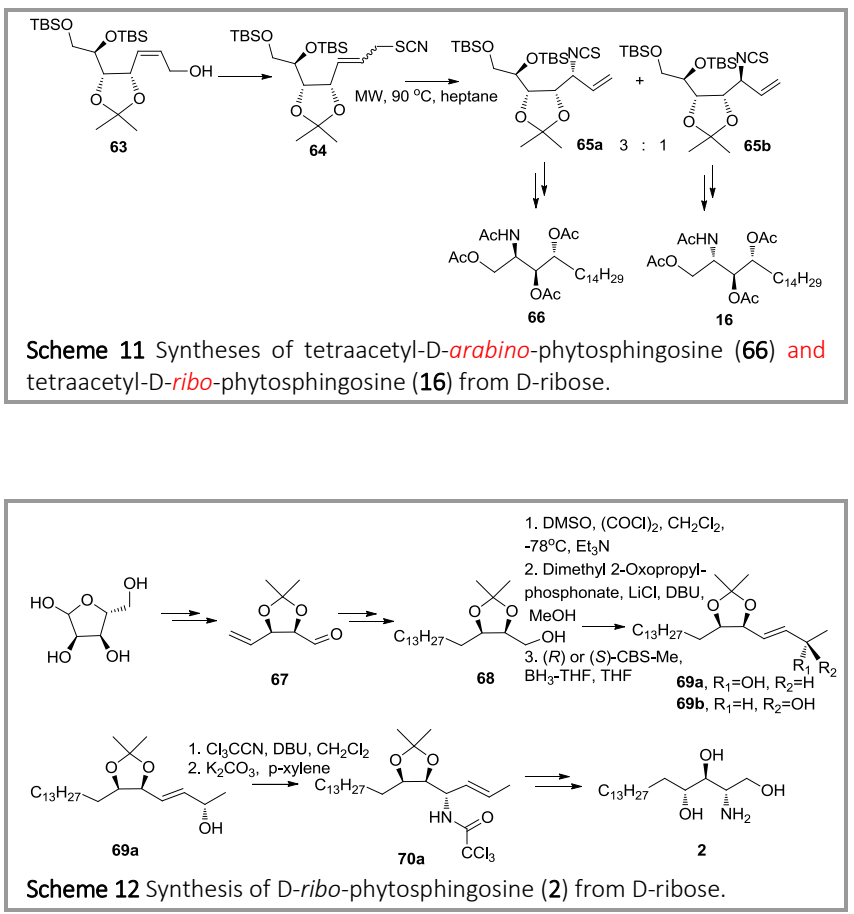

\subsubsection{Chirality from D-fructose}

In 2011, a new methodology for synthses of D-ribo-phytosphingosine (2) and L-arabino-phytosphingosine (77) from D-fructose was developed by Perali (Scheme 13). ${ }^{36}$ In this scheme, zincmediated fragmentation of $\mathbf{7 1}$ was used as key step to give the cerresponding ketone. Interestingly, subsequent reduction by $\mathrm{NaBH}_{4}$ almost yielded $\mathbf{7 2} \mathbf{b}$, corresponding to $\mathbf{7 2 a}$ as major product $(\mathbf{7 2 a}: \mathbf{7 2 b}=7: 3)$ via reduction by $\operatorname{LiAlH}\left(\mathrm{O}^{-} \mathrm{Bu}\right)_{3}$. Both $\mathbf{7 2 a}$ and $\mathbf{7 2 b}$ were subjected to crucial olefin cross-metathesis for chain extention, azido substitution, and other simple conversions to successfully afford 2 . To note, the reason for retention of configuration at $\mathrm{C} 2$ position from $\mathbf{7 4 b}$ to $\mathbf{2}$ was that substitution of 74b by $\mathrm{NaN}_{3}$ underwent $\mathrm{S}_{\mathrm{N}} 1$ type substitution. To invert this configuration, Mitsunobu reaction was finally utilized, thus, Larabino-phytosphingosine (77) was obtained from compound 75. 


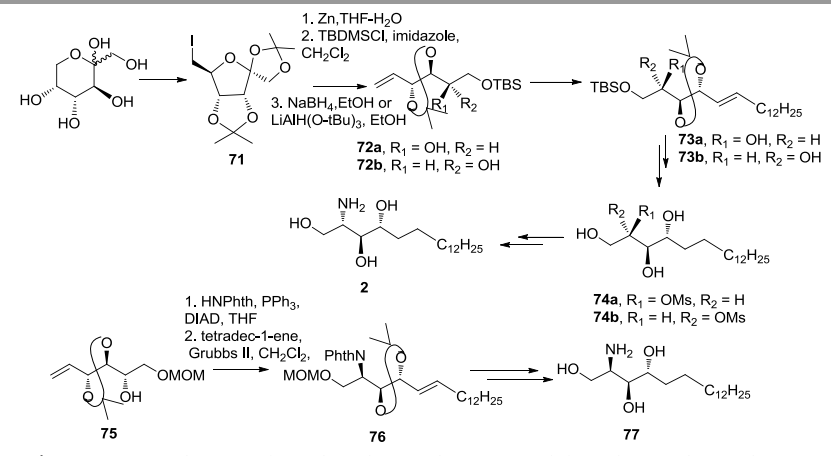

Scheme 13 Syntheses of D-ribo-phytosphingosine (2) and L-arabino-phytosphingosine (77) starting from D-fructose.

\subsection{Chirality from serine and its derivatives}

\subsubsection{Chirality from serine ester}

In 2002, Chuang group presented a short and efficient route for synthesis of all four stereomers of sphingosine from serine (Scheme 14). ${ }^{37}$ The authors employed HWE olefination to form trans double bond in high yield. Treatment of 3-ketosphingosine derivative 78 with $\mathrm{NaBH}_{4}$ in the presence of $\mathrm{CeCl}_{3} \cdot 7 \mathrm{H}_{2} \mathrm{O}$ afforded syn reduction product, which leaded to further prepare L-threosphingosine (79) and its acetyl derivative (80). However, reduction of deprotection product of $\mathbf{7 8}$ by $\mathrm{Zn}\left(\mathrm{BH}_{4}\right)_{2}$ gave anti reduction product, which was subjected to further conversion to D-erythrosphingosine (1) and its acetyl derivative (18). According to the same procedure, L-erythro-sphingosine and D-threo-sphingosine were easily prepared from $\mathrm{D}$-serine methyl ester $\mathrm{HCl}$. The similar stereoselective reduction protocol was also employed by Katsumura and Bittman to synthesize D-erythro-sphingosine (1) from L-serine or $\mathrm{N}$-Boc-L-serine methyl ester. ${ }^{38}$ Olefin crossmetathesis and elimination of sulfoxide intermediate was respectively utilized by Katsumura and Bittman to construct trans double bond.

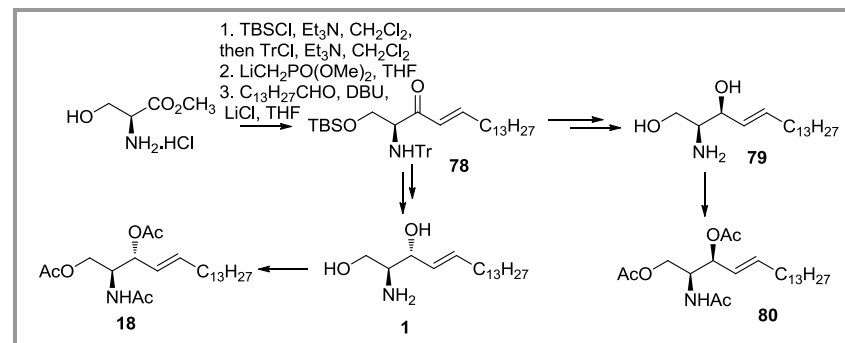

Scheme 14 Syntheses of compound 1, 18, 79 and 80 from L-serine methyl ester $\mathrm{HCl}$.

Liebeskind reported a concise and very efficient synthesis of Derythro-sphingosine (1) from N-Boc-L-serine over 6 steps in $72 \%$ overall yield in 2007 (Scheme 15). 39 In this work, new methodology for cross-coupling between thiol ester $\mathbf{8 1}$ and vinyl boronic has been developed to construct the classic alkenyl ketone intermediate $\mathbf{8 2}$, which was further subjected to stereoselective reduction mentioned above to give the target compound 1.

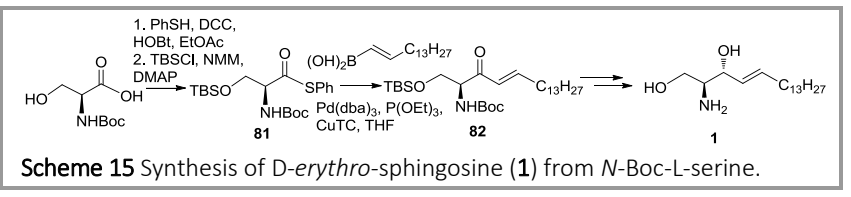

An efficient, stereocontrolled synthetic method for the preparation of D-xylo-phytosphingosine (4) and D-arabinophytosphingsine (3) was reported by Ham et al in 2012 starting from L-serine methyl ester via chiral 1,3-oxazines intermediate (Scheme 16). ${ }^{40}$ The crucial reactions involved stereoselective intramolecular oxazine formation catalyzed by palladium (0) and $\mathrm{CM}$ reaction for chain extention. Notably, both $85 \mathrm{a}$ and $\mathbf{8 5 b}$ could be separately obtained as major products by changing the reaction temperature. 85 a leaded to give $D$-xylo-phytosphingosine (4), however, $85 \mathrm{~b}$ leaded to give D-arabino-phytosphingosine (3) in the same manner.

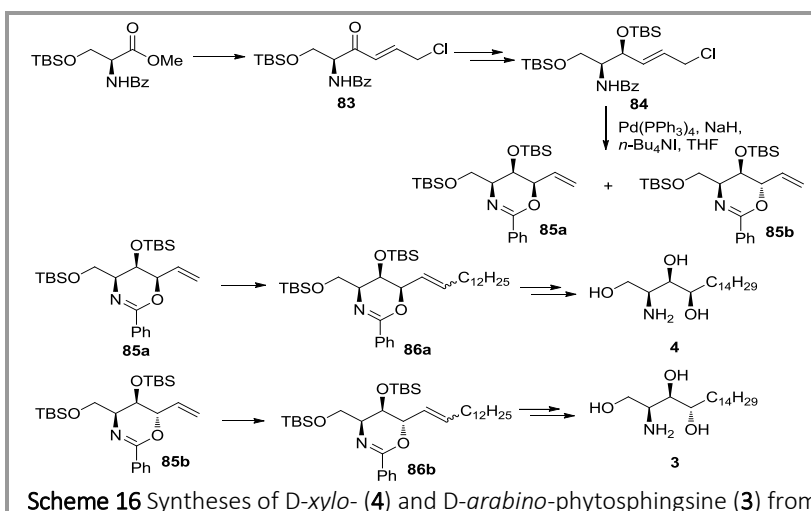

Scheme 16 Syntheses of D-xylo- (4) and D-arabino-phytosphingsine (3) from L-serine methyl ester.

\subsubsection{Chirality from Garner's aldehyde}

In 2002, Murakami ${ }^{41 a}$ achieved efficient and high diastereoselective syntheses of $\mathrm{N}$-Boc-D-erythro-sphingosine (88a) and $\mathrm{N}$ Boc-L-threo-sphingosine (88b) using addition of 1-alkenyl nucleophiles to Garner's aldehyde as pivotal steps (Scheme 17). Notably, addition of 1-alkenylzirconocene chloride to Garner's aldehyde in the presence of $\mathrm{ZnBr}_{2}$ gave anti-isomer, conversely, addition of 1-alkenyl-ethyl-zinc to Garner's aldehyde afforded synisomer. An alternative synthesis of intermediate $\mathbf{8 7 a}$ a was reported by Arenz through addition of Garner's aldehyde by vinylmagnesium bromide and subsequent $\mathrm{CM}$ reaction in $37 \%$ yield. ${ }^{41 \mathrm{~b}}$ The similar addition of 1-alkenyl nucleophile to Garner's aldehyde to prepare D-erythro-sphingosine was also employed by Ferjančić in 2014 using alkenylchromium (III) reagent instead, however, with a lower diastereoselectivity (7:1) and yield (46\%) compared with Murakami's protocol. ${ }^{42 a}$ In contrast, Montgomery took advantage of nickel-catalyzed reductive coupling of Garner's aldehyde with silyl alkyne to give compound 87c with good yield (78\%) and satisfactory diastereoselectivity (>95:5), which easily converted into 87 a over 2 steps. ${ }^{42 b}$

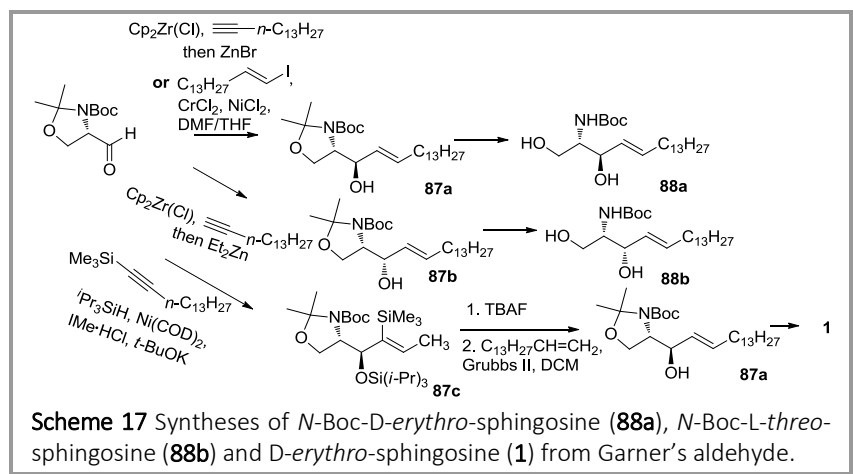

A short and convenient synthesis of D-erythro-sphingosine (1) was accomplished by Cárdennas's group over 4 steps in 33\% 
overall yield from Garner's acid in 2013 (Scheme 18). ${ }^{43}$ Key steps included efficient addition of terminal alkyne to benzotriazole esters (89a, 89b) and stereoselective reduction.

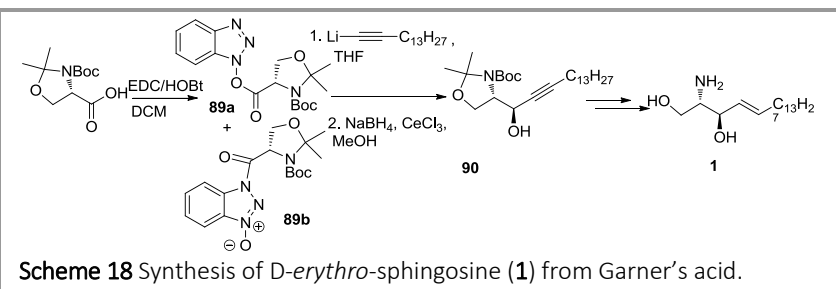

Unlike Lomobardo's strategy, Kim et al employed $\mathrm{OsO}_{4}$-catalyzed dihydroxylation reactions of (Z)-allylic amines derived from (Z)selective Wittig olefination of Garner's aldehyde to set the stereochemistry at C3, C4 positions. ${ }^{44}$ As shown in Scheme 19, dihydroxylation of (Z)-allylic amine with $N, N$-diBoc groups gave anti-selective isomer 92a, however, dihydroxylation of $\mathrm{N}$-Boc-(Z)allylic amine (91) gave syn-selective isomer $\mathbf{9 2 b}$. This can be explained by severe 1,2-allylic strain between the $\mathrm{N}, \mathrm{N}$-diBoc groups and the vinylic hydrogen atom. The stereocontrolled dihydroxylation of (Z)-allylic amines was better than Sharpless dihydroxylation to some degree, upon which syntheses of both tetraacetyl derivatives of D-ribo-phytosphingosine (16) and Larabino-phytosphingosine (93) were achieved.

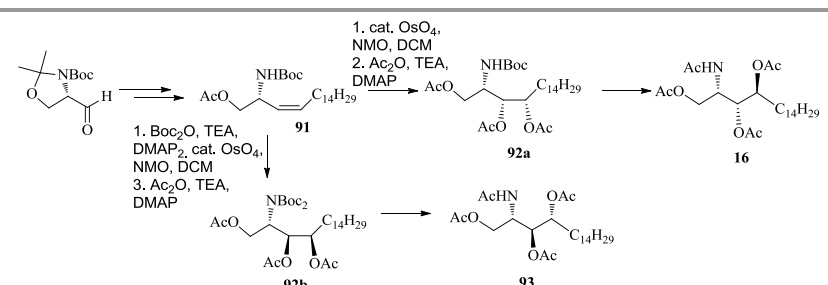

Scheme 19 Syntheses of both tetraacetyl derivatives of D-ribo-phytosphingosine (16) and L-arabino-phytosphingosine (93) from Garner's aldehyde.

\subsection{Chirality from D-ribo-phytosphingosine}

Since D-ribo-phytosphingosine is easily accessible from a yeast fermentation process, it has been used as chiral pool to prepare sphingosine and other phytosphingosines. Several syntheses of Derythro-sphingosine from D-ribo-phytosphingosine have been achieved in a concise manner (Scheme 20). ${ }^{45}$ The common point of these syntheses was selective protection of C1-hydroxy and C2- amine groups followed by elimination of a cyclic sulfate intermediate (95, 97 and 99) to exclusively construct trans olefin. Aside from elimination of a cyclic sulfate intermediate, epoxide (101) ${ }^{46}$ and alcohol (104) ${ }^{47}$ were also eliminated to give trans olefin. Different from the above protocols, van Boom ${ }^{48}$ has employed stereoselective transformation of $\mathbf{1 0 2}$ into the corresponding (Z)-enol triflate (103) followed by a regiospecific reduction to install trans double bond. Among these syntheses, Overkleeft ${ }^{45 c}$ has provided a short synthetic route with highest overall yield (67\%) to date.

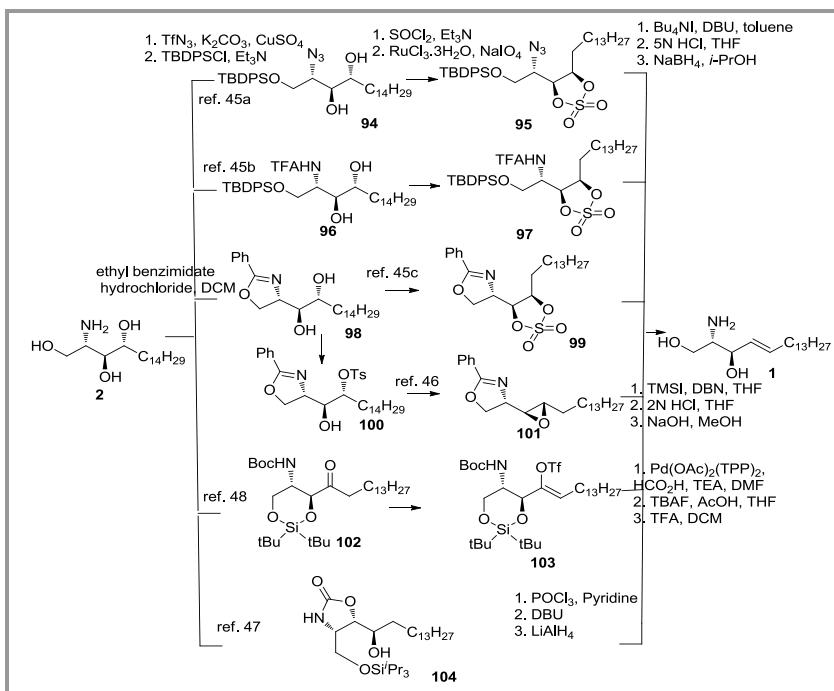

Scheme 20 Synthesis of D-erythro-sphingosine (1) from D-ribo-phytosphingosine (2) through different routes.

D-ribo-phytosphingosine works as important chiral pool, it was also used to prepare other phytosphingosines. Kim reported highyielding and concise syntheses of D-arabino-(3), D-lyxo-(5), and Dxylo-phytosphingosine (4) from D-ribo-phytosphingosine (2) (Scheme 21). ${ }^{49}$ The configurational inversion of $\mathrm{C}-4$ of compound 2 which leaded to afford D-lyxo-phytosphingosine (5) was carried out via cyclic sulfate intermediate $\mathbf{1 0 5}$ or oxonium ion intermediate 108 attacked by nucleophiles. On the other hand, inversion of C-3 and C4 leaded to D-arabino-phytosphingosine (3), and inversion of C-3 leaded to D-xylo-phytosphingosine (4). Both were carried out via mesylate intermediate attacked by nucleophiles $\left(\mathrm{H}_{2} \mathrm{O}\right)$.

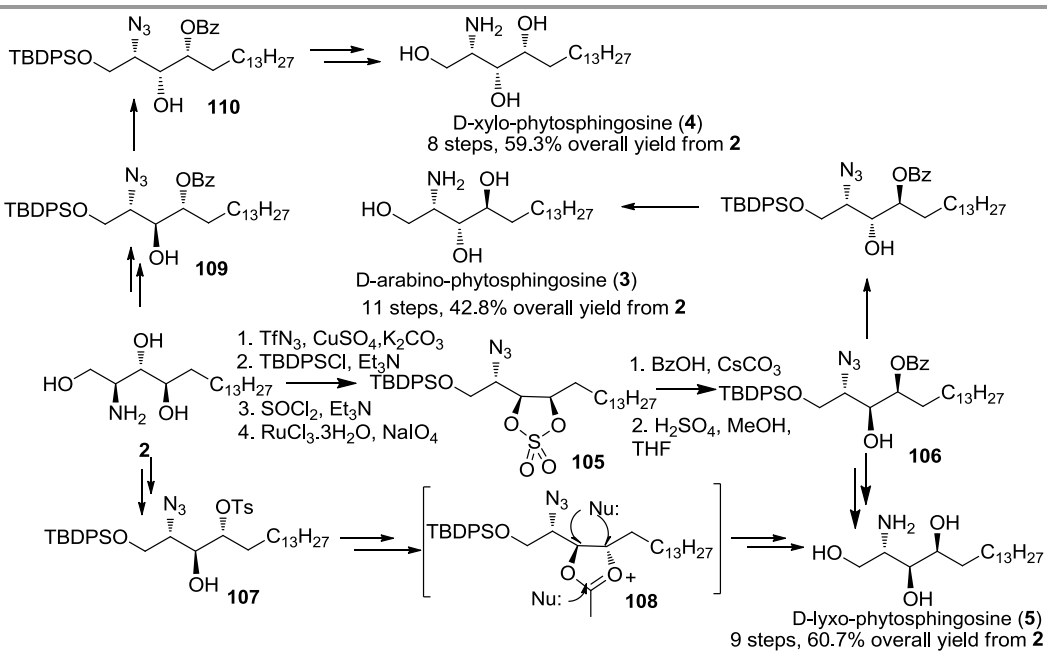

Scheme 21 Syntheses of D-arabino-phytosphingosine (3), D-lyxo-phytosphingosine (5), and D-xylo-phytosphingosine (4) from D-ribo-phytosphingosine (2).

\subsection{Chirality from D-tartric acid and its diester}


In 2004, Basu ${ }^{50}$ employed two contiguous hydroxyl groups of Dtartrate diester as chiral template to accomplish the synthesis of protected D-erythro-azidosphingosine (113) (Scheme 22). The highlight of this work was selective benzoylation of azidotriol 111 and exclusive formation of trans olefin via cross metathesis. However, compound $\mathbf{1 1 3}$ was obtained in a low yield (36\%). Another formal synthesis of D-erythro-azidosphingosine from Dtartrate diester was reported by Panza ${ }^{51}$ in 2002 taking advantage of Julia olefination of sulfone $\mathbf{1 1 5}$ to construct trans olefin in a $E / Z$ ratio of $5: 1$ in $53 \%$ yield.

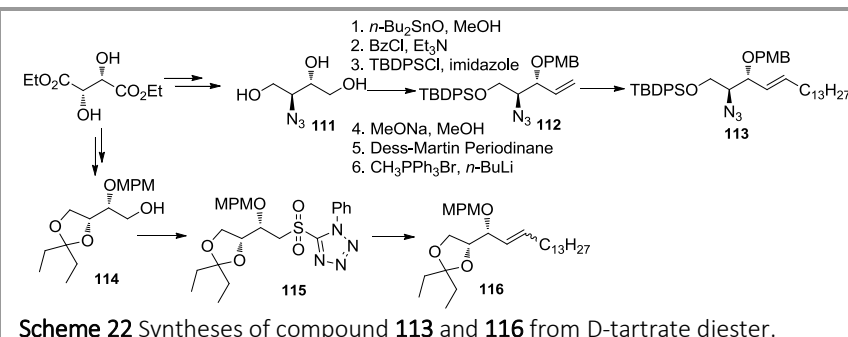

Bittman ${ }^{52}$ has achieved the synthesis of $\mathrm{Lg}_{\mathrm{g}}$-lyxo-phytosphingosine (5) employing diastereoselective addition of the Grignard reagent to aldehyde $\mathbf{1 1 7}$ derived from $\mathrm{D}$-tartric acid to give a mixture of $118 \mathrm{a}$ and $\mathbf{1 1 8 b}$ in a ratio of 9:1 (Schem 23). Another crucial step was convertion of diol to azido $\mathbf{1 1 9}$ by Mitsunobu's procedure. According to the same synthetic procedure for 5, Dribo-phytosphingosine (2) was also prepared from compound $\mathbf{1 1 8 b}$ which was obtained from 118a via Mitsubobu reaction.

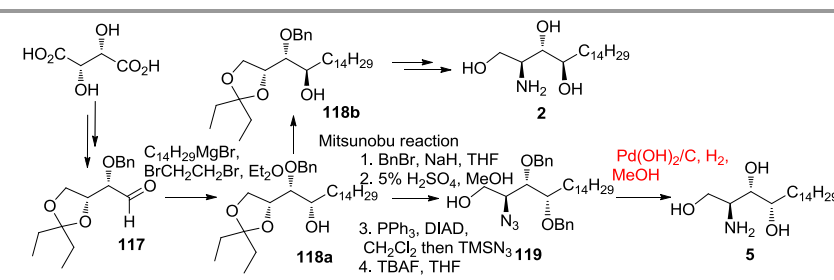

Scheme 23 Syntheses of $\mathrm{L}_{\mathrm{g}}-1 y \times 0$-phytosphingosine (5) and D-ribo-phytosphingosine (2) from $D$-tartric acid.

Shiozaki ${ }^{53}$ has provided an alternative access to D-erythrosphingosine (1) and $\mathrm{L}_{\mathrm{g}}$-lyxo-phytosphingosine (5) using chiral $\beta$ lactam 120 derived from $D$-tartrate diester as chiral template (Scheme 24). Ring-opening reaction of $\beta$-lactam 120 by 4 tolyltetrade-cylsulfone followed by elimination afforded key ketone 122 in a satisfactory yield (93\%). Isomerization of ketone 122 to enol triflate $\mathbf{1 2 3}$, then reductive elimination and deprotection yielded $\mathrm{N}$-Boc-D-erythro-sphingosine (88a) in a moderate yield. On the other hand, diastereoselective reduction of $\mathbf{1 2 2}$ by $\mathrm{LiEt}_{3} \mathrm{BH}$ gave protected aminotriol $\mathbf{1 2 4}$ in good yield and stereoselectivity, which further converted into 5 in an excellent yield (96\%).

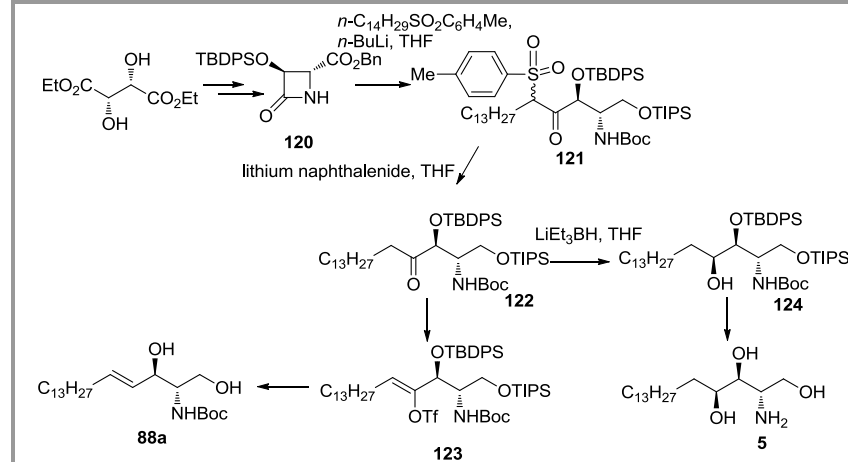

Scheme 24 Syntheses of $\mathrm{Lg}$-lyxo-phytosphingosine (5) and N-Boc-D-erythrosphingosine (88a) from D-tartrate diester.

\subsection{Chirality from other chiral precursors}

Concise, efficient and enantiodivergent syntheses of D- and Lerythro-sphingosine ( $\mathbf{1}$ and ent-1) were achieved by Merino et $a$ l in 2006. ${ }^{54}$ As shown in scheme 25 , the key steps involved a stereocontrolled Mannich-type reaction between D-glyceraldehyde nitrone 125 and 2-silyloxy silylketene acetal, and a trans-selective Wittig olefination. Interestingly, Mannich-type reaction conducted in the presence of $\mathrm{SnCl}_{2}, \mathrm{Yb}(\mathrm{OTf})_{3}$, or $\mathrm{Zn}(\mathrm{OTf})_{2}$ gave compound 126a as major product, on the other hand, when using $\mathrm{SnCl}_{4}$ as promoter gave compound $\mathbf{1 2 6 b}$ as major product. L-erythrosphingosine (ent-1) was prepared according to the same procedure as described for 1 from 126a.

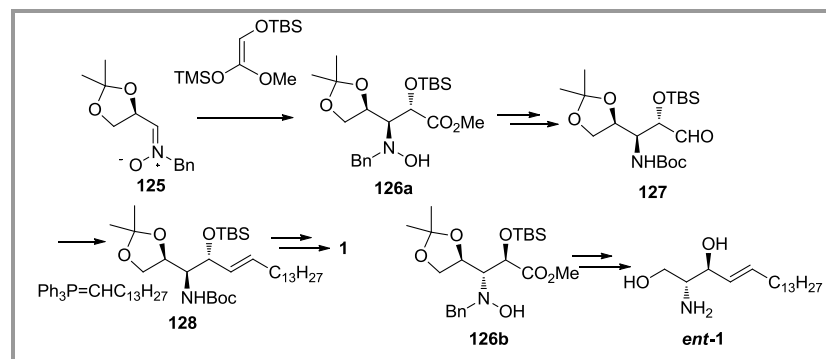

Scheme 25 Syntheses of D- and L-erythro-sphingosine (1 and ent-1) from Dglyceraldehyde nitrone.

Rao's group ${ }^{55}$ has reported a stereoselective synthesis of N,O,O,O-tetraacetyl D-lyxo-phytosphingosine (ent-48) over 10 steps from a known intermediate ${ }^{55 b}$ derived from L-ascorbic acid. The crucial reactions involved Grignard addition on epoxide $\mathbf{1 2 9}$ and stereoselective addition of chiral imine $\mathbf{1 3 1}$ by vinylmagnesium bromide (Scheme 26).



Scheme 26 Synthesis of N,O,O,O-tetraacetyl D-lyxo-phytosphingosine (ent-48) from L-ascorbic acid.

Aside from the above chiral precursors, Sarabia and his coauthors employed L-methionine as chiral pool to synthesize cyclic sulfonium salt 133, which was successfully applied to synthesize Derythro-sphingosine (1) and D-ribo-phytosphingosine (2) over 7 steps, 13 steps, respectively (Scheme 27). ${ }^{56}$ Highlight of this work was stereoselective formation of epoxide amide (134, 135 or 138) 
and regioselective epoxide-opening reaction by amino or azide nucleophile at $\mathrm{C} 2$ position.

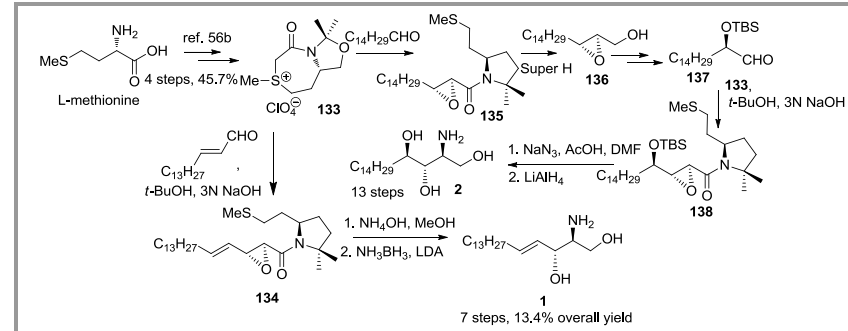

Scheme 27 Syntheses of D-erythro-sphingosine (1) and D-ribo-phytosphingosine (2) from L-methionine.

\section{Chiral auxiliary}

\subsection{Chiral sulfur auxiliary}

A high-yielding and facile synthesis of D-erythro-sphingosine (1) was achieved by Castillón et al in 2008 in $42 \%$ overall isolated yield with 6 steps (Scheme 27). ${ }^{56}$ The success of this work was employing asymmetric sulfur ylide reaction between the sulfonium salt 139 and the aldehyde $\mathbf{1 4 0}$ to construct the epoxide 141 with the desired configuration. In addition, $E$-selective $\mathrm{CM}$ for chain extension and a regio-, stereoselective intramolecular epoxideopening reaction to form oxazolidinone $\mathbf{1 4 2}$ were also crucial for the synthesis.

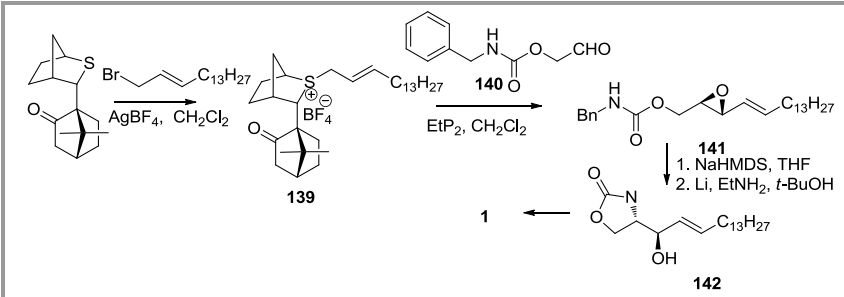

Scheme 28 Synthesis of D-erythro-sphingosine (1) from chiral sulfur auxiliary.

Aside from the above sulfur auxiliary, Wei et al ${ }^{58}$ has introduced a novel chiral $\mathbf{N}$-tert-butanesulfinamide $\mathbf{1 4 5}$ for cross-coupling with bulky long-chain aliphatic aldehydes $\mathbf{1 4 4}$ derived from D-glutamic acid to stereoselectively install amino functionality at $\mathrm{C} 2$ position and hydroxyl functionality at $\mathrm{C} 3$ position, thus, an efficient synthesis of D-ribo-phytosphingosine (2) was accomplished (Scheme 29) over 5 steps in $27 \%$ overall yield from known compound $143 .{ }^{58 b}$

$$
\text { D-Glutamic acid } \stackrel{\text { ref. 58b }}{\longrightarrow}
$$

Scheme 29 Synthesis of D-ribo-phytosphingosine (2) from D-glutamic acid

\subsection{Chiral N-containing auxiliary}

Similar to Wei's protocol, ${ }^{58 a}$ chiral iminoglycinate $\mathbf{1 4 7}$ was used by Bundle et $\mathrm{al}^{59}$ to condense with alehyde to build amino group at C2 position and hydroxyl group at C3 postion, therefore, iminoglycinate condensed with acrolein to give truncated sphingosine 149 in a concise manner. On the other hand, iminoglycinate condensed with aldehyde containing a $R$ or $S$ configuration hydroxyl group to give D-ribo-phytosphingosine (2) and L-lyxo-phytosphingosine (5) in more than $45 \%$ overall yield in both cases (Scheme 30).

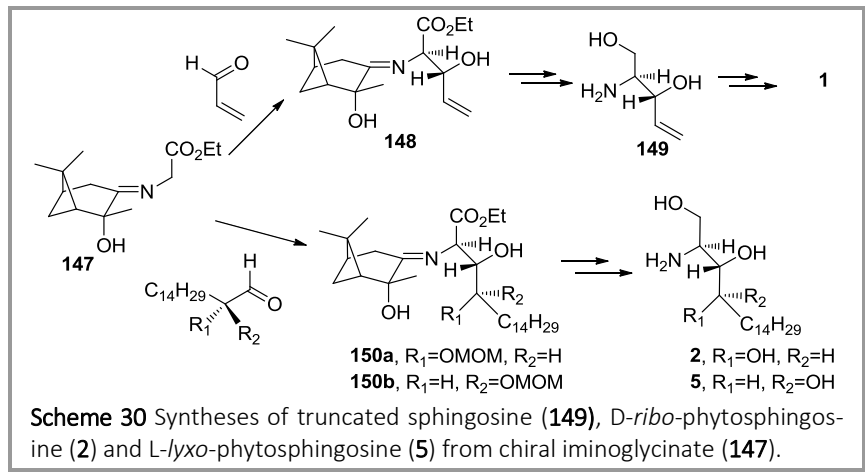

Ishikawa ${ }^{60}$ has reported a synthesis of D-erythro-sphingosine (1) using chirality transfer from chiral guanidinium ylide 151 to 3alkenyl aziridine-2-carboxylate (153a and 153b) to build chiral amino alcohol unit in $\mathbf{1}$ (Scheme 31). In this work, chiral guanidinium ylide 151 reacted with $\alpha, \beta$-unsaturated aldehyde 152 to give a mixture of cis/trans (ca. 1:1) aziridine-2-carboxylate without diastereoselectivity. However, both diastereoisomers can be further converted into compound $\mathbf{1}$ via oxazolidinone intermediates (155a or $\mathbf{1 5 5 b}$ ). To note, cis-aziridine-2-carboxylate (153b) was subjected to ring-opening reaction followed by $\mathrm{S}_{\mathrm{N}} 2$ type substitution to invert the hydroxyl configuration at the $\mathrm{C} 3$ position.

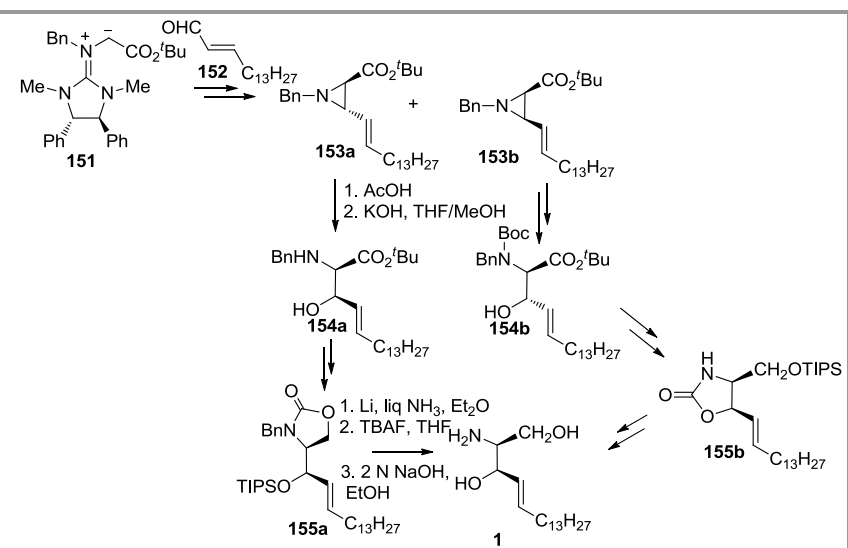

Scheme 31 Synthesis of D-erythro-sphingosine (1) from chiral guanidinium ylide 151 .

\section{Asymmetric reactions}

A number of syntheses of sphingosines and phytosphingosines have been accomplished from achiral starting materials using asymmetric reactions to set chiral hydroxyl groups, or chiral amino groups, or both. The extensive literatures searching revealed they could be classified into five categories: Sharpless dihydroxylation, Sharpless epoxidation and Shi's epoxidation, catalytic asymmetric aldol reaction, Sharpless kinetic resolution, asymmetric aminohydroxylation and amination.

\subsection{Sharpless dihydroxylation reaction}

Very recently, Sudalai et al ${ }^{61}$ has reported an enantioselective synthesis of tetraacetyl-D-ribo-phytosphingosine (16) starting from 1-hexadecanol taking advantage of L-proline-catalyzed $\alpha$-amino- 
oxylation, Horner-Wardsworth-Emmons olefination for E-selective olefin and Sharpless asymmetric dihydroxylation as the pivotal reactions (Scheme 32). Besides, regioselective sulfonylation of diol 157 at the $\alpha$-position of the ester was also necessary for the synthesis. Prior to Sudalai's synthesis, Bittman ${ }^{62}$ employed a similar synthesis of $\mathbf{1 6}$ via the common intermediate $\mathbf{1 5 6}$ from 1hexadecene. Sharpless dihydroxylation reaction was utilized twice by Bittman to install the three continous stereogenic centers in $\mathbf{1 6}$. Minor difference from Sudalai's strategy was that the synthesis of $\alpha$-aizdoester 158 was carried out through regioselective $\alpha$-azidation of the cyclic sulfate of dihydroxyl ester $\mathbf{1 5 7}$. This strategy was also sucessfully employed by Bittman to synthesize D-erythrosphingosine (1) commencing with 1-pentadecyne.

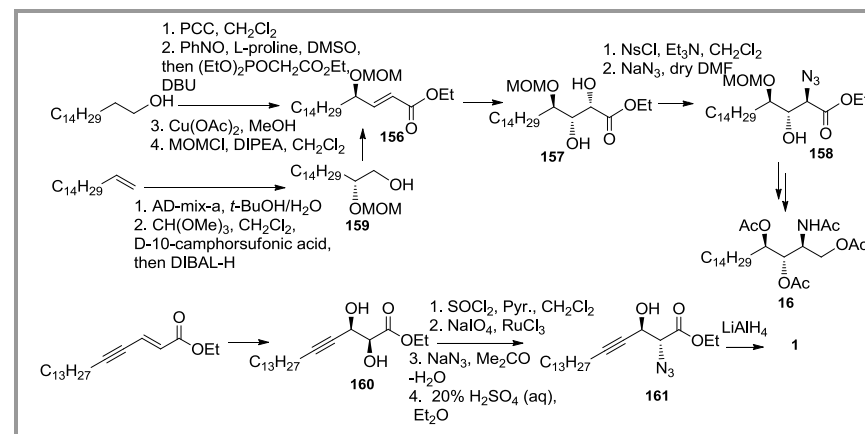

Scheme 32 Syntheses of tetraacetyl-D-ribo-phytosphingosine (16) and Derythro-sphingosine (1)

Matheu has reported efficient and high-yielding syntheses of Derythro-sphingosine (1) and D-ribo-phytosphingosine (2) via common cyclic sulfate intermediate 164 over 7 steps in 44\%, 53\% overall yield, respectively (Scheme 33 ). ${ }^{64}$ The desired chirality was obtained by dynamic kinetic resolution of butene epoxide and sequential Sharpless hydroxylation. Elimination of compound 164 gave compound 1 , on the other hand, ring-opening by $\mathrm{BzOH}, \mathrm{CsCO}_{3}$ further provided compound $\mathbf{2}$.

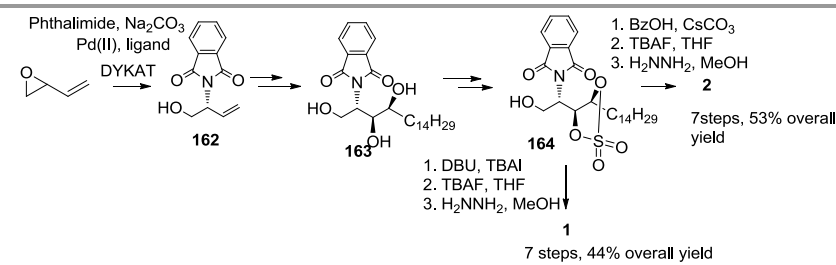

Scheme 33 Syntheses of D-erythro-sphingosine (1) and D-ribo-phytosphingosine (2) from butadiene monoepoxide.

\subsection{Sharpless epoxidation and Shi's epoxidation reaction}

Somfai et al ${ }^{65}$ has reported the synthesis of Bn-protected Derythro-sphingosine (168) utilizing Shi's epoxidation, regioselective opening reactions of vinyl epoxide $\mathbf{1 6 6}$ and vinylaziridine $\mathbf{1 6 7}$ in the allylic position as crucial steps (Scheme 34). Notably, no regioseletivity was observed during Shi's epoxidation of diene 165 so as to give a mixture of 2,3-epoxy olefin 166 and 4,5-epoxy olefin. Later, Somfai et al described an improved strategy to synthesize Derythro-sphingosine (1) from divinylcarbinol over 5 steps in $51 \%$ overall yield. Highlight of the strategy was Sharpless epoxidation, subsequent Payne rearrangement, a regioselective ring-opening reaction and $E$-selective cross-metathesis for chain extension.

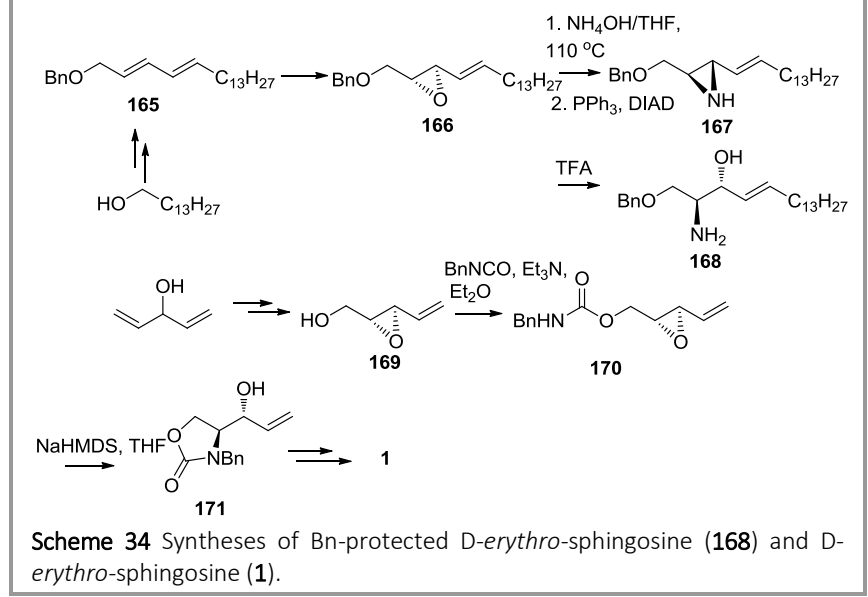

Righi et al ${ }^{66}$ has described an efficient approach to synthsize Derythro-sphingosine (1) and D-lyxo-phytosphingosine (5) based on Wittig olefination, stereoselective addition of the common aldehyde 174, respectively (Scheme 35). The aldehyde 174 was derived from (Z)-4-benzyloxy-2-buten-1-ol employing Sharpless epoxidation and following regioselective ring-opening reactions as key steps. Notably, Wittig olefination of $\mathbf{1 7 4}$ didn't gave trans olefin in a satisfactory selectivity $(E / Z=7 / 3)$.

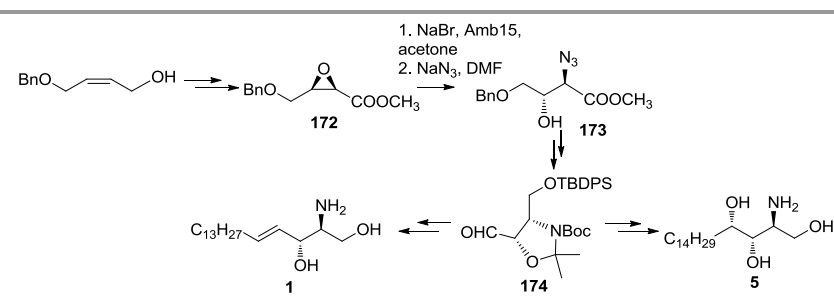

Scheme 35 Syntheses of D-erythro-sphingosine (1) and D-lyxo-phytosphingosine (5) from (Z)-4-benzyloxy-2-buten-1-ol.

\subsection{Asymmetric aldol reaction}

In 2006, Enders's group 67a reported concise and straightforward syntheses of D-arabino-phytosphingosine (3) and protected L-ribophytosphingosine (181) via the common ketone 178 with 6 steps in $49 \%, 38 \%$ overall yield, respectively (Scheme 36 ). The stereogenic centers at $\mathrm{C} 3, \mathrm{C} 4$ positions were introduced by $(S)$-prolinecatalyzed aldol reaction of 2,2-dimethyl-1,3-dioxan-5-one and pentadecanal with excellent diastereo- and enantiomeric excess (>99\%, 95\% respectively). While the configuration at C2 position was installed by stereoselective reduction of ketone. To improve the diastereoselectivity during the reduction, hydroxyl group at $\mathrm{C} 4$ position was protected as its silyl ether. On the other hand, the adol reaction was catalyzed by $(R)$-proline giving compound ent178 with 59\% yield and good diastereo-and enantioselectivity (>99\%, 95\% respectively), and compound ent-178 further converted into D-ribo-azidophytosphingosine (182). ${ }^{67 b}$ 


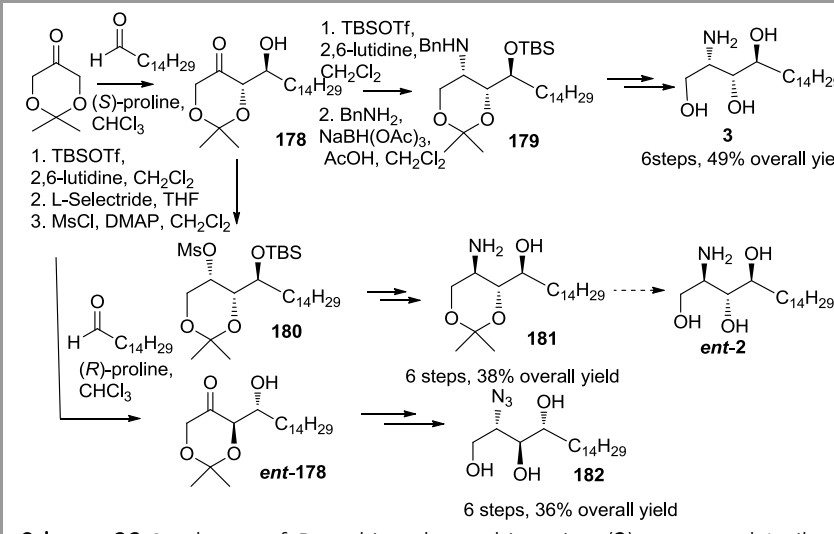

Scheme 36 Syntheses of D-arabino-phytosphingosine (3), protected L-ribophytosphingosine (181) and D-ribo-azidophytosphingosine (182) from 2,2dimethyl-1,3-dioxan-5-one.

Kobayashi ${ }^{68}$ has reported an efficient synthesis of L-erythrosphingosine (ent-1) from (E)-4-((tert-butyldiphenylsilyl)oxy)but-2enal over 7 steps with $16 \%$ overall yield. The key steps involve a chiral zirconium complex catalyzed aldol reaction of aldehyde by silicon enolate 183 and cross coupling of acetate with Grignard reagent (Scheme 37). Notably, the aldol reaction successfully introduced the desired chiral hydroxyl and amino groups of compound $\mathbf{1 8 4}$ in a high yield (95\%) and moderate stereoselectivity (anti/syn=8/2).

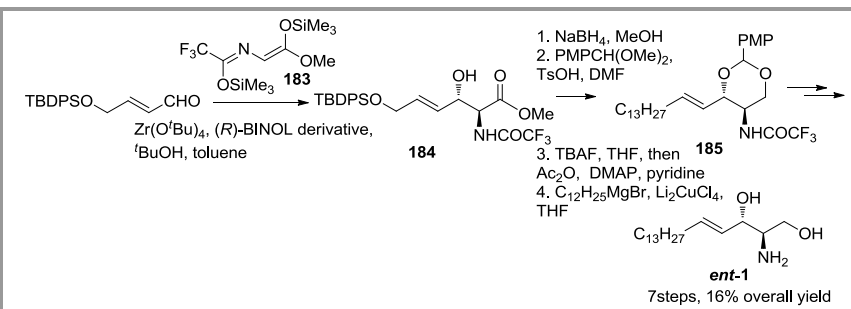

Scheme 37 Synthesis of L-erythro-sphingosine (ent-1) from (E)-4-((tert-butyldiphenylsilyl)oxy)but-2-enal.

\subsection{Sharpless kinetic resolution}

Barua ${ }^{69}$ has reported a facile and flexible synthesis of D-ribophytosphingosine (2) from achiral trans-cinnamaldehyde over 13 steps in $15.6 \%$ overall yield (Scheme 38 ). The stereocenters at C3, C4 positions were obtained by Sharpless kinetic resolution of homoallylic alcohol 186 , while the stereocenter at $\mathrm{C} 2$ postion was obtained by a regioselective epoxide-opening reaction. Another highlight of the synthesis was oxidative cleavage of phenyl ring by $\mathrm{NaIO}_{4} / \mathrm{RuCl}_{3} \cdot \mathrm{H}_{2} \mathrm{O}$

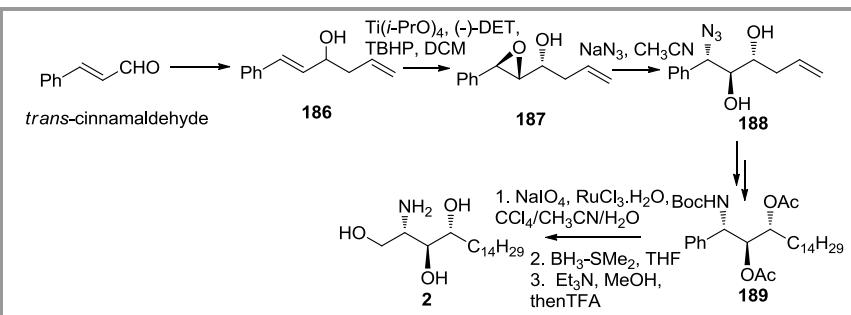

Scheme 38 Synthesis of D-ribo-phytosphingosine (2) from trans cinnamaldehyde.

Like Barua's protocol, Kumar 70 has also employed Sharpless kinetic resolution to introduce the stereocenter at C3 postion in the syntheses of $\mathrm{N}$-Boc-L-threo-sphingosine (88b) and tetraacetyl-Darabino-phytosphingosine (66) (Scheme 39). And the syn stereochemistry of amino group at C2 position was installed by a tethered aminohydroxylation in a moderate yield (65-66\%). Both compound $\mathbf{8 8 b}$ and 66 were synthesized over 8 steps in $8 \%, 11 \%$ overall yield, respectively.

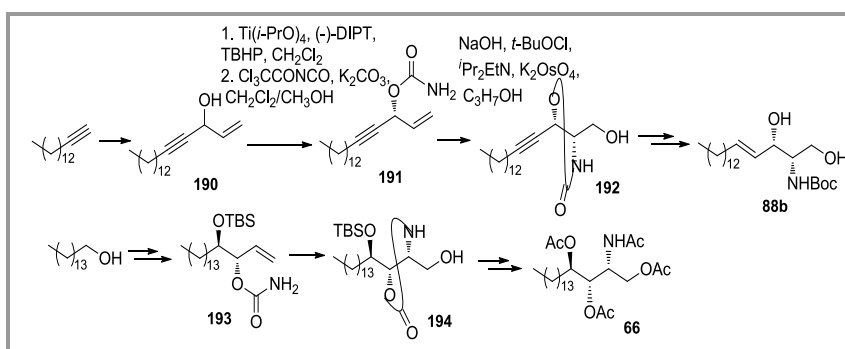

Scheme 39 Syntheses of $N$-Boc-L-threo-sphingosine (88b) and tetraacetyl-Darabino-phytosphingosine (66) from 1-pentadecyne and 1-pentadecanol, respectively.

\subsection{Asymmetric aminohydroxylation and amination}

In 2008, Davies et al reported divergent and efficient syntheses of N,O,O-triacetyl-D-erythro-sphingosine (18), tetraacetyl-D-lyxophytosphingosine (ent-48) and tetraacetyl-D-ribo-phytosphingosine (16) from the common intermediate oxazolidine aldehyde 197 (Scheme 40). 71 Wittig olefination of oxazolidine aldehyde 197 leaded to give compound 18 , and the $E$-selectivity $(E / Z=94 / 6)$ was carried out by quenching the reaction with methanol. On the other hand, addition of compound 197 by Grignard reagent gave a 90:10 mixture of alcohol 199a and 199b, which further converted into compound ent-48 and 16, respectively. Highlight of the protocol was highly diastereoselective conjugate addition of unsaturated ester 195 followed by in situ enolate oxidation with (camphorsulfonyl)oxaziridine (CSO).

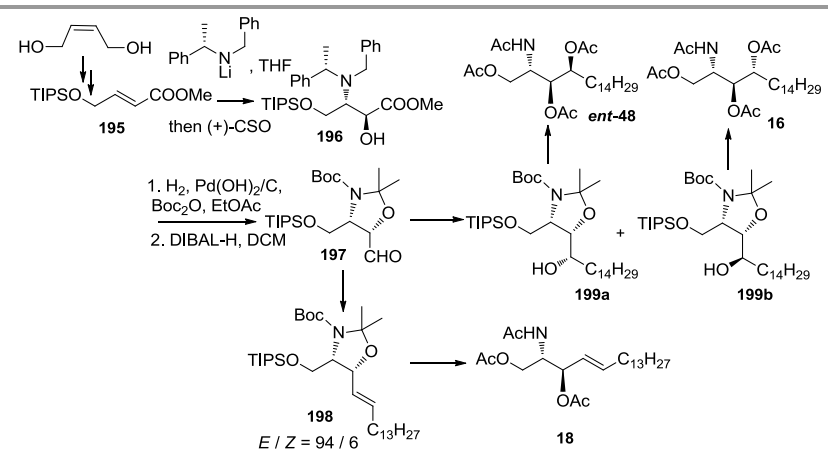

Scheme 40 Syntheses of $\mathrm{N}, \mathrm{O}, \mathrm{O}$-triacetyl-D-erythro-sphingosine (18), tetraacetyl-D-lyxo-phytosphingosine (ent-48) and tetraacetyl-D-ribo-phytosphingosine (16) from cis-but-2-ene-1,4-diol.

Same as Davies's protocol, Han ${ }^{72}$ also employed an asymmetric aminohydroxylation reaction of $\alpha, \beta$-unsaturated ester 200 to introduce the stereocenters at $\mathrm{C} 2, \mathrm{C} 3$ postions with high regioselectivity (>20:1) and enantioselectivity (>99\%). While the stereochemistry at $\mathrm{C} 4$ position was set by a high diastereoselective (>10:1) addition of aldehyde 201 by Grignard reagent. Thus, Nacetyl L-xylo-phytosphingosine (202) was obtained with 5 steps in $22 \%$ overall yield (Scheme 41). An alternative synthesis of 202 could also be achieved through a two-step manipulation on compound 203. On the other hand, the stereochemical interconversion of the hydroxyl group at $\mathrm{C} 4$ postion was carried out by treatment of compound 203 with $\mathrm{MsCl} / \mathrm{Et}_{3} \mathrm{~N}$ via oxazine intermediate 204, which further converted into $\mathrm{N}$-acetyl L-arabinophytosphingosine (206).

In 2013, Helmchen ${ }^{73}$ reported a novel synthesis of D-erythrosphingosine (1) in 9 linear steps and 5\% overall yield (scheme 42). 
Highlight of the scheme was a chiral iridium-catalyzed allylic amination to set the chiral carbamate 207 in a high yield $(87 \%)$ and enantioselectivity (98\%). The other pivotal reactions involved ringclosing metathesis (RCM) and stereoselective epoxidationregioselective elimination reaction.
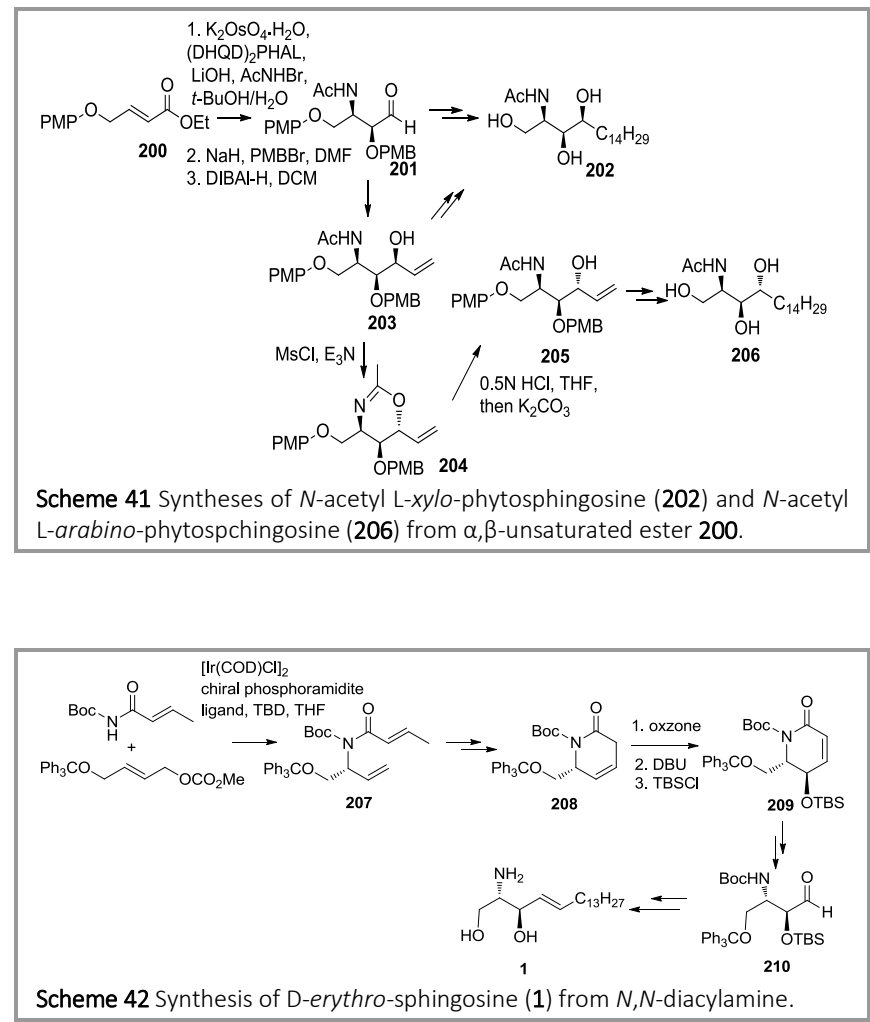

\section{Conclusions}

Sphingosines and phytosphingosines have drawn increased attention from the synthetic chemists' community in recent years because of their various physiological activities. Two key points of theses syntheses were introduction of stereochemistry and extension of a long aliphatic chain. Chiral pool approaches, chiral auxiliary and asymmetric reactions are the three main strategies to set stereogenic centers. Among them, chiral pool strategy which was concise and efficient with short synthetic route, high yield, and high optical purity usually seemed to be more acceptable. Meanwhile, chiral auxiliary and asymmetric reactions provided candidate strategies to synthesize sphingosines and phytosphingosines from various starting materials, which could be more flexible and straightforward in some cases. And the protocol for chain elongation often employed Wittig olefination, olefin cross metathesis and nucleophilic addition by Grignard reagent. The protocols with higher yield, shorter synthetic route, higher enantioselectivity, higher diastereoselective, and better versatility for the syntheses of the library of sphingosines and phytosphingosines are still expected in future.

\section{Acknowledgment}

This work was supported by Natural Science Foundation of Hubei Province of China (No. 2015CFB333) for Youth Fund and Hubei Chenguang Talented Youth Development Foundation, China.

\section{References}

(1) (a) Merrill, A. H., Jr.; Sandhoff, K. Sphingolipids: Metabolism and Cell Signaling. In Biochemistry of Lipids, Lipoprotein, and Membranes; Vance, D. E.; Vance, J. E., Eds. Elsevier: New York, 2002, 373. (b) Kobayashi, E.; Motoki, K.; Yamaguchi, Y.; Uchida, T.; Fukushima, H.; Koezuka, Y. Bioorg. Med. Chem. 1996, 32, 133. (c) Spiegel, S.; Milstein, S. J. Biol. Chem. 2002, 277, 25851. Mathias, S.; Pena, L. A.; Kolesnick, R. N. Biochem. J. 1998, 335, 465. (d) Birbes, H.; Bawab, S. E.; Obeid, L. M.; Hannun, Y. A. Adv. Enzyme Regul. 2002, 42, 113.

(2) (a) Hannun, Y. A.; Loomis, C. R.; Merrill, A. H. Jr; Bell, R. M. J. Biol. Chem. 1986, 261, 12604. (b) Hannun, Y.; Bell, R. M. Science 1989, 243, 500. (c) Hannun, Y. Science 1996, 274, 1855. (d) Vankar, Y. D.; Schmidt, R. R. Chem. Soc. Rev. 2000, 29, 201. (e) Brodesser, S.; Sawatzki, P.; Kolter, T. Eur. J. Org. Chem. 2003, 2021. (f) Springer, T. A.; Lasky, L. A. Nature 1991, 349, 196. (g) Feizi, T. Trends Biochem. Sci. 1991, 16, 84.

(3) Thudichum, J. L. W. A Treatise on the Chemical Constitution of the Brain 1884, Lontoo: Bailliere. New edition 1962, Archon Books, Hamden, Connecticut, USA.

(4) Carter, H. E.; Glick, F. J.; Norris, W. P.; Phillips, G. E. J. Biol. Chem. 1947, 170, 285.

(5) Shapiro, D.; Segal, H. J. Am. Chem. Soc. 1954, 76, 5894

(6) Higuchi, R.; Kagoshima, M.; Komori, T. Liebigs Ann. Chem. 1990, 659.

(7) Okabe, K.; Keeman, R. W.; Schmidt, G. Biochem. Biophys. Res. Commun. 1968, 31, 137.

(8) Barenholz, Y.; Gatt, S. Biochem. Biophys. Res. Commun. 1967, 27, 319.

(9) Karlsson, K. A.; Samuelsson, B. E.; Steen, G. O. Acta Chem. Scand. 1968, 22, 1361.

(10) Kobayashi, E.; Motoki, K.; Yamaguchi, Y.; Uchida, T.; Fukushima, H.; Koezuka, Y. Bioorg. Med. Chem. 1996, 4, 615.

(11) Gonzalez-Aseguinolaza, G.; Kaer, L. V.; Bergmann, C. C.; Wilson, J. M.; Schmieg, J.; Kronenberg, M.; Nakayama, T.; Taniguchi, M.; Koezuka, Y.; Tsuji, M. J. Exp. Med. 2002, 195, 617.

(12) Tamiya-Koizumi, K.; Murate, T.; Suzuki, M.; Simbulan, C. M. G.; Nakagawa, M.; Takemura, M.; Furuta, K.; Izuta, S.; Yoshida, S. Biochem. Mol. Biol. Int. 1997, 41, 1179.

(13) Dickson, R. C.; Nagiec, E. E.; Skrzypek, M.; Tillman, P.; Wells, G. B.; Lester, R. L. J. Biol. Chem. 1997, 272, 30196.

(14) International Union of Biochemistry Biochemical Nomenclature and Related Documents, The Biochemical Society, London, 1978.

(15) (a) Howell, A. R.; Ndakala, A. J. Current Organic Chemistry 2002, 6, 365. (b) Koskinen, P. M.; Koskinen, A. M. P. Synthesis 1998, 1075. (c) Morales-Serna, J. A.; Llaveria, J.; Díaz, Y.; Matheu, M. I.; Castillón, S. Current Organic Chemistry 2010, 14, 2483. (d) Liao, J. Y.; Tao, J. H.; Lin, G. Q.; Liu, D. G. Tetrahedron 2005, 61, 4715. (e) Curfman, C.; Liotta, D. Methods Enzymol. 1999, 311, 391.

(16) Pandey, G.; Tiwari, D. K. Tetrahedron Lett. 2009, 50, 3296

(17) Banik, B. K.; Mathur, C.; Wagle, D. R.; Manhas, M. S.; Bose, A. K. Tetrahedron 2000, 56, 5603.

(18) (a) Mettu, R.; Thatikonda, N. R.; Olusegun, O. S.; Vishvakarma, R.; Vaidya, J. R. ARKIVOC 2012, 421. (b) Compostella, F.; Franchini, L.; Giovenzana, G. B.; Panza, L.; Prosperib, D.; Ronchettia, F. Tetrahedron: Asymmetry 2002, 13, 867.

(19) Martinková, M.; Pomikalová, K.; Gonda, J.; Vilková, M. Tetrahedron 2013, 69, 8228.

(20) Chiu, H. Y.; Tzou, D. M.; Patkar, L. N.; Lin, C. C. J. Org. Chem. 2003, $68,5788$.

(21) Lin, C. C.; Fan, G. T.; Fang, J. M. Tetrahedron Lett. 2003, 44, 5281.

(22) Chang, C. W.; Chen, Y. N.; Adak, A. K.; Lin, K. H.; Tzou, D. M.; Lin, C. C. Tetrahedron 2007, 63, 4310.

(23) Compostella, F.; Franchini, L.; Libero, G.; Palmisano, G.; Ronchettia, F.; Panza, L. Tetrahedron 2002, 58, 8703.

(24) Milne, J. E.; Jarowicki, K.; Kocienski, P. J.; Alonso, J. Chem. Commun. 2002, 426

(25) Rao, G. S.; Chandrasekhar, B.; Rao, B. V. Tetrahedron: Asymmetry 2012, 23, 564. 
(26) Chaudhari, V. D.; Kumar, K. S. A.; Dhavale, D. D. Org. Lett. 2005, 7, 5805.

(27) Luo, S. Y.; Thopate, S. R.; Hsub, C. Y.; Hung, S. C. Tetrahedron Lett. 2002, 43, 4889.

(28) Cai, Y.; Ling, C. C.; Bundle, D. R. Carbohydr. Res. 2009, 344, 2120.

(29) (a) Duclos Jr, R. I. Chemistry and Physics of Lipids 2001, 111,111.

(b) Parameswar, A. R.; Hawkins, J. A.; Mydock, L. K.; Sands, M. S.; Demchenko, A. V. Eur. J. Org. Chem. 2010, 3269.

(30) Schmidt, R. R.; Zimmermann, P. Tetrahedron Lett. 1986, 27, 481.

(31) Figueroa-Pérez, S.; Schmidt, R. R. Carbohydr. Res. 2000, 328, 95.

(32) Niu, Y.; Cao, X.; Ye, X. S. Helvetica Chimica Acta 2008, 91, 746.

(33) Martinková, M.; Pomikalová, K.; Gonda, J. Chemical Papers 2013, $67,84$.

(34) Martinková, M.; Gonda, J.; Pomikalova, K.; Kožišek, J.; Kuchar, J. Carbohydr. Res. 2011, 436, 1728.

(35) Calder, E. D. D.; Zaed, A. M.; Sutherland, A. J. Org. Chem. 2013, 78, 7223.

(36) Perali, R. S.; Mandava, S.; Chalapala, S. Tetrahedron 2011, 67, 9283.

(37) Lee, J. M.; Lim, H. S.; Chung, S. K. Tetrahedron: Asymmetry 2002, 13, 343.

(38) (a) Yamamoto, T.; Hasegawa, H.; Hakogi, T.; Katsumura, S. Org. Lett. 2006, 8, 5569; (b) Chun, J.; Li, G.; Byun, H. S.; Bittman, R. Tetrahedron Lett. 2002, 43, 375.

(39) Yang, H.; Liebeskind, L. S. Org. Lett. 2007, 9, 2993;

(40) Mu, Y.; Jin, T.; Kim, G. W.; Kim, J. S.; Kim, S. S.; Tian, Y. S.; Oh, C. Y.; Ham, W. H. Eur. J. Org. Chem. 2012, 2614.

(41) (a) Murakami, T.; Furusawa, K. Tetrahedron 2002, 58, 9257. (b) Bhabak, K. P.; Proksch, D.; Redmer, S.; Arenz, C. Bioorg. Med. Chem. 2012, 20, 6154.

(42) (a) Ferjančić, Z.; Matović, R.; Bihelović, F. J. Serb. Chem. Soc. 2014, 79, 627. (b) Sa-ei, K.; Montgomery, J. Tetrahedron 2009, 65, 6707.

(43) Morales-Serna, J. A.; Sauza, A.; de Jesús, G. P.; Gaviño, R.; de la Mora, G. G.; Cárdenas, J. Tetrahedron Lett. 2013, 54, 7111.

(44) Jeon, J.; Shin, M.; Yoo, J. W.; Oh, J. S.; Bae, J. G.; Jung, S. H.; Kim, Y. G. Tetrahedron Lett. 2007, 48, 1105.

(45) (a) Kim, S.; Lee, S.; Lee, T.; Ko, H.; Kim, D. J. Org. Chem. 2006, 71, 8661. (b) Lee, Y. M.; Lee, S.; Jeon, H.; Baek, D. J.; Seo, J. H.; Kim, D.; Kim, S. Synthesis 2011, 867. (c) van den Berg, R. J. B. H. N.; van den Elst, H.; Korevaar, C. G. N.; Aerts, J. M. F. G.; van der Marel, G. A.; Overkleeft, H. S. Eur. J. Org. Chem. 2011, 6685.

(46) van den Berg, R. J. B. H. N.; Korevaar, C. G. N.; Overkleeft, H. S.; van der Marel, G. A.; van Boom, J. H. J. Org. Chem. 2004, 69, 5699.

(47) Ha, H. J.; Yoon, D. H.; Kang, L. S.; Hong, M. C.; Lee, W. K. Bull. Korean Chem. Soc. 2009, 30, 353.

(48) van den Berg, R. J. B. H. N.; Korevaar, C. G. N.; van der Marel, G. A.; Overkleeft, H. S.; van Boom, J. H. Tetrahedron Lett. 2002, 43, 8409.

(49) Kim, S.; Lee, N.; Lee, S.; Lee, T.; Lee, Y. M. J. Org. Chem. 2008, 73, 1379.

(50) Rai, A. N.; Basu, A. Org. Lett. 2004, 6, 2861.

(51) Compostella, F.; Franchini, L.; Panza, L.; Prosperi, D.; Ronchetti, F. Tetrahedron, 2002, 58, 4425.

(52) Lu, X. Q.; Bittman, R. Tetrahedron Lett. 2005, 46, 3165.

(53) Nakamura, T.; Shiozaki, M. Tetrahedron 2001, 57, 9087.

(54) Merino, P.; Jimenez, P.; Tejero, T. J. Org. Chem. 2006, 71, 4685.

(55) (a) Rao, G. S.; Rao, B. V. Tetrahedron Lett. 2011, 52, 6076. (b) Elie, A.; Purushotham, V.; Robert, W. L.; Haribansh, K. S.; Amarendra, B. M.; David, C. J.; Racha, S.; Raymond, P. P. J. Org. Chem. 1988, 53, 2598.

(56) (a) Sarabia, F.; Vivar-García, C.; García-Ruiz, C.; Sánchez-Ruiz, A.; Pino-González, M. S.; García-Castro, M.; Chammaa, S. Eur. J. Org. Chem. 2014, 3847. (b) Sarabia, F.; Vivar-García, C.; García-Castro, M.; García-Ruiz, C.; Martín-Gálvez, F.; Sánchez-Ruiz, A.; Chammaa, S. Chem. Eur. J. 2012, 18, 15190.

(57) Morales-Serna, J. A.; Llaveria, J.; Díaz, Y.; Matheu, M. I.; Castillón, S. Org. Biomol. Chem. 2008, 6, 4502.

(58) (a) Xarnod, C.; Huang, W.; Ren, R. G.; Liu, R. C.; Wei, B. G. Tetrahedron 2012, 68, 6688. (b) Liu, R. C.; Huang, W.; Ma, J. Y.; Wei, B. G.; Lin, G. Q. Tetrahedron Lett. 2009, 50, 4046.
(59) Cai, Y.; Ling, C. C.; Bundle, D. R. Org. Biomol. Chem. 2006, 4, 1140

(60) Disadee, W.; Ishikawa, T. J. Org. Chem. 2005, 70, 9399.

(61) Venkataramasubramanian, V.; Kumar, B. S.; Sudalai, A. Tetrahedron: Asymmetry 2015, 26, 571.

(62) He, L. L.; Byun, H. S.; Bittman, R. J. Org. Chem. 2000, 65, 7618.

(63) He, L. L.; Byun, H. S.; Bittman, R. J. Org. Chem. 2000, 65, 7627.

(64) Llaveria, J.; Díaz, Y.; Matheu, M. I.; Castillón, S. Org. Lett. 2009, 11, 205.

(65) (a) Torssell, S.; Somfai, P. Org . Biomol . Chem. 2004, 2, 1643. (b) Olofsson, B.; Somfai, P. J. Org. Chem. 2003, 68, 2514

(66) Righi, G.; Ciambrone, S.; D’Achille, C.; Leonellia, A.; Bonini, C. Tetrahedron 2006, 62, 11821.

(67) (a) Enders, D.; Paleček, J.; Grondal, C. Chem. Commun. 2006, 655. (b) Enders, D.; Terteryan, V.; Paleček, J. Synthesis 2010, 2979.

(68) Kobayashi, J.; Nakamura, M.; Mori, Y.; Yamashita, Y.; Kobayashi, S. J. Am. Chem. Soc. 2004, 126, 9192.

(69) Devi, T. J.; Saikia, B.; Barua, N. C. Tetrahedron 2013, 69, 3817.

(70) Kumar, P.; Dubey, A.; Puranik, V. G. Org. Biomol. Chem. 2010, 8 , 5074.

(71) (a) Abraham, E.; Brock, E. A.; Candela-Lena, J. I.; Davies, S. G.; Georgiou, M.; Nicholson, R. L.; Perkins, J. H.; Roberts, P. M.; Russell, A. J.; Sánchez-Fernández, E. M.; Scott, P. M.; Smith, A. D.; Thomson, J. E. Org. Biomol. Chem. 2008, 6, 1665. (b) Abraham, E.; Davies, S. G.; Millican, N. L.; Nicholson, R. L.; Roberts, P. M.; Smith, A. D. Org. Biomol. Chem. 2008, 6, 1655.

(72) Singh, O. V.; Kampf, D. J.; Han, H. Tetrahedron Lett. 2004, 45, 7239.

(73) Hoecker, J.; Rudolf, G. C.; Bächle, F.; Fleischer, S.; Lindner, B. D.; Helmchen, G. Eur. J. Org. Chem. 2013, 5149. 


\section{Biographical sketches}

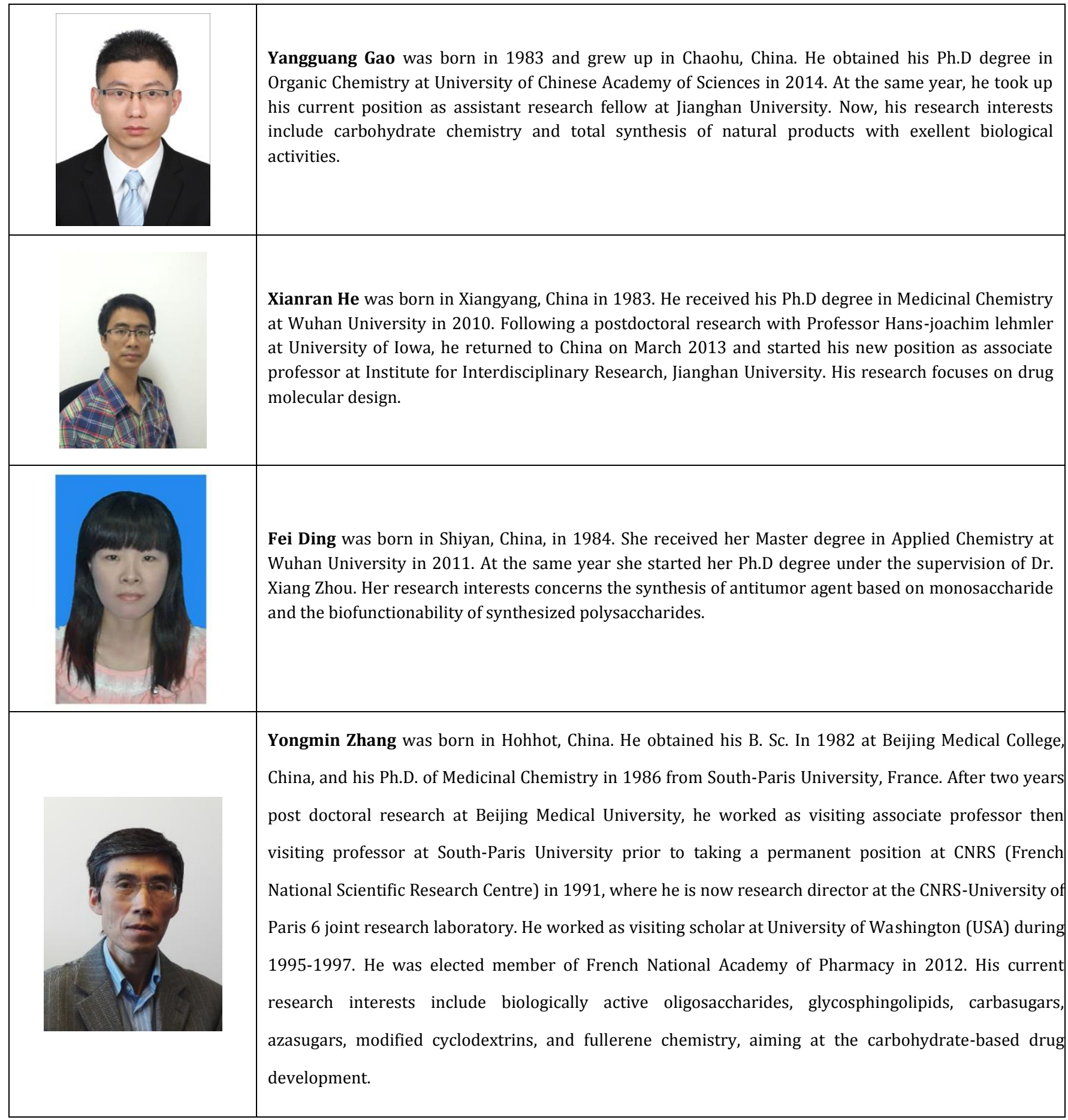

